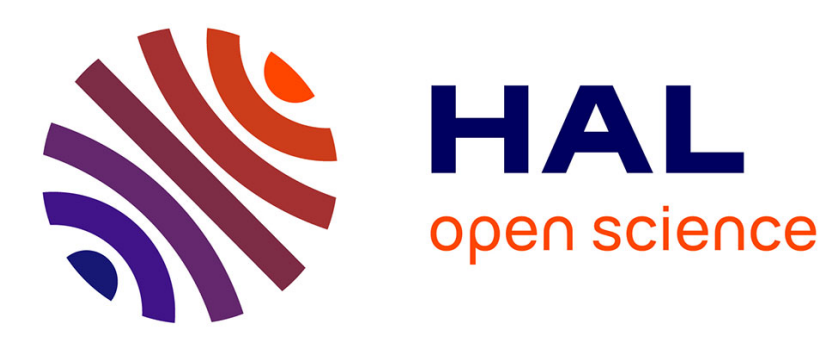

\title{
Corniches et couronnements gallo-romains à Alésia (Alise-Sainte-Reine, Côte-d'Or)
}

\author{
Albéric Olivier
}

\section{To cite this version:}

Albéric Olivier. Corniches et couronnements gallo-romains à Alésia (Alise-Sainte-Reine, Côted'Or). Gallia - Fouilles et monuments archéologiques en France métropolitaine, 1989, 46, pp.43-69. 10.3406/galia.1989.2891 . hal-01939634

\section{HAL Id: hal-01939634 \\ https://hal.science/hal-01939634}

Submitted on 12 Feb 2020

HAL is a multi-disciplinary open access archive for the deposit and dissemination of scientific research documents, whether they are published or not. The documents may come from teaching and research institutions in France or abroad, or from public or private research centers.
L'archive ouverte pluridisciplinaire HAL, est destinée au dépôt et à la diffusion de documents scientifiques de niveau recherche, publiés ou non, émanant des établissements d'enseignement et de recherche français ou étrangers, des laboratoires publics ou privés.

\section{(ㅇ)(1) $\$$}

Distributed under a Creative Commons Attribution - NonCommercial - NoDerivatives $\mid 4.0$ 


\title{
CORNICHES ET COURONNEMENTS GALLO-ROMAINS À ALÉSIA (ALISE-SAINTE-REINE, CÔTE-D'OR)*
}

\author{
par Albéric OLIVIER
}

L'étude des blocs d'architecture d'Alésia a mis en évidence plusieurs séries de corniches à modillons qui ont pu être mises en relation avec des monuments, et permis de proposer des éléments de chronologie. D'autre part, l'étude des blocs de couronnement décorés de $\mathrm{S}$ liés à des acrotères à palmettes, a montré que ce décor n'orne pas seulement des édicules mais aussi des édifices de grande dimension; le remontage d'un fronton ainsi cọ̆onné a permis de préciser la place de ces divers éléments.

The study of the architectural blocks from Alesia shows that there were several series of modillion-cornices which could be related to monuments and which can provide us with chronological data.

(II) In addition, the study of the summit blocks decorated with a double-S motif linked with palmette shaped acroteria n's that this type of ornament was used to decorate not only small ediculae, but also large buildings.

The reconstruction of a fronton crowned in this manner has enabled us to determine the exact position of each of thiss elements.

Depuis 1906, le musée Alésia a conservé les débris et fragments d'architecture qui proviennent du plateau du Mont-Auxois (bourg gallo-romain, sanctuaire de Moritasgus) et des alentours immédiats. Les travaux d'inventaire récents sur les blocs d'architecture ont permis d'effectuer des classements par série. Ici, il sera question des corniches : ce sont des éléments très peu publiés en Gaule du Nord-Est.

* Je tiens à remercier Monsieur J. Le Gall, Mesdemoiselles S. Deyts et E. Rabeisen, des fouilles d'Alésia, qui ont autorisé, encouragé et facilité ce travail. Mes remerciements vont aussi à la classe de tailleurs de pierre et à son professeur, Monsieur H. Belli, du lycée d'enseignement professionnel des Marcs d'Or de Dijon, qui ont réalisé la reconstitution du fronton de la chapelle de "la déesse aux amours" pour sa présentation muséographique au musée Alésia : certaines déductions doivent beaucoup à leurs observations de professionnels de la taille de pierre. Pour la relation de cette opération, voir E. Rabeisen et A. Olivier, Des lycéens reconstituent un monument d'Alésia, Archéalogia, 228, 1987, p. 28-37.
Les blocs d'architecture ont été, la plupart du temps, trouvés dans des puits, des sous-sols ou des dépressions comblées, quand ils n'ont pas èté réemployés. Dans le cas particulier des corniches et des couronnements, la partie moulurée et ornée a été souvent laissée pour compte par les récupérateurs de matériaux, car peu utilisable : les débris sont très fragmentés et infimes par rapport au volume des constructions antiques. Leur appartenance à un monument est délicate à affirmer, car souvent, le lieu de découverte n'est pas un argument suffisant; cependant, il a été possible, lors de ce travail, d'obtenir quelques certitudes sur leur localisation et même de proposer pour certains blocs une place précise dans un édifice.

Pour l'étude chronologique et stylistique, les fragments sont peu nombreux : cependant, ils sont suffisants pour caractériser au moins quatre variantes appartenant toutes à la série des corniches à modillons. En l'absence de point d'ancrage sûr comme une inscription ou un contexte stratigraphique, il est illusoire de vouloir les dater mais, en 
DÉCORS DES SOFFITES

VUE DE DESSOUS

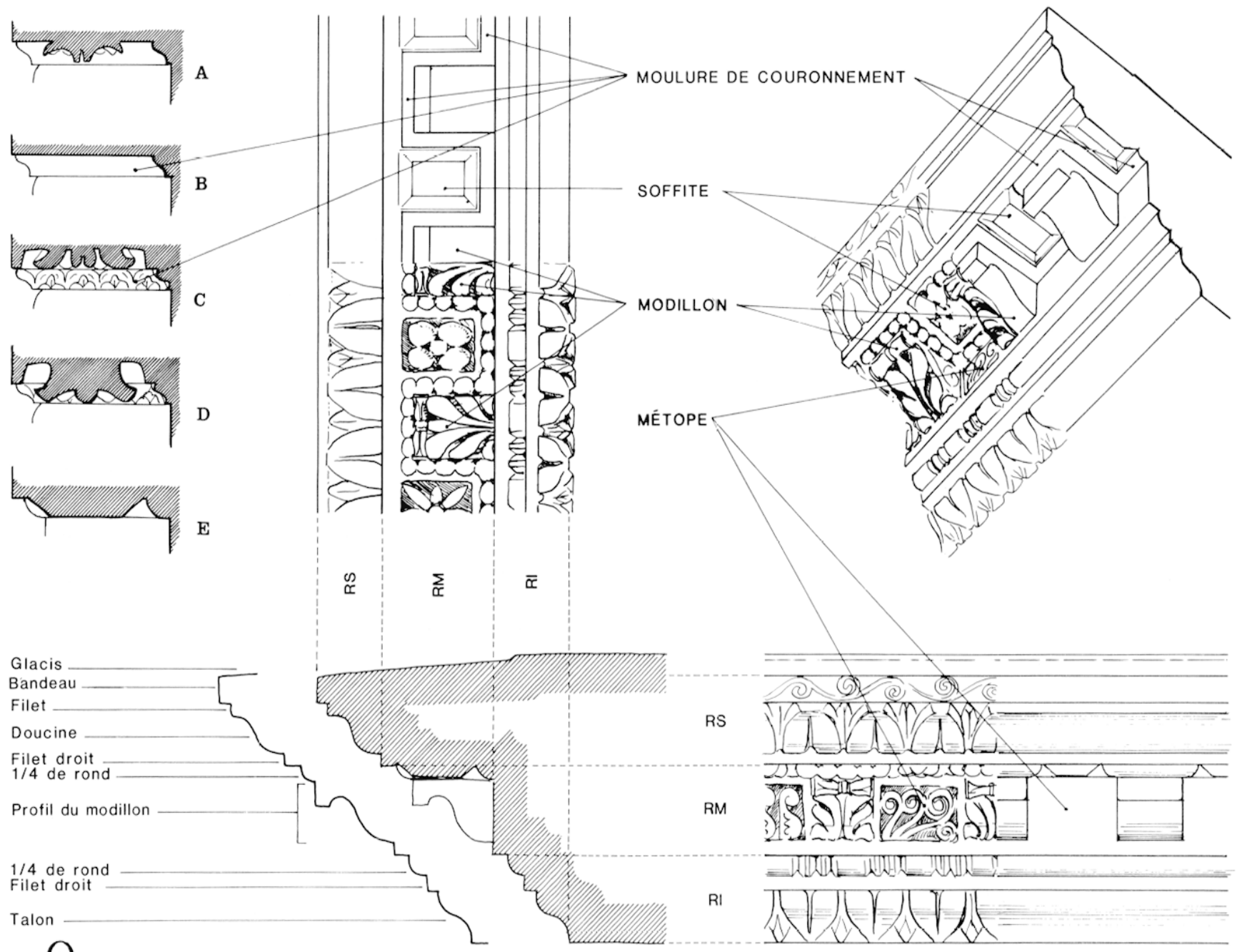

Q

PROFIL DE L'EPANNELAGE

Fig. 1 - Corniche modillonnaire, vocabulaire.

RI : registre inférieur; RM : registre médian; RS : registre supérieur; A : soffite à fleuron saillant; $\mathrm{B}:$ soffite lisse; C : soffite à fleuron encaissé ; D : soffite à fleuron encaissè et saillant; $\mathrm{E}$ : épannelage des solutions $\mathrm{A}$ et $\mathrm{D}$.

revanche, il est possible de tenter un classement en chronologie relative. Pour les couronnements, Alésia a le privilège de conserver deux variantes de blocs ornés de $\mathbf{S}$ qui posent un problème architectural original : la restitution récente de la chapelle de "la déesse aux amours" apporte, en situant les blocs à leur vraie place, un éclairage intéressant sur ces éléments fréquents dans la région.

\section{STRUCTURE ET VOCABULAIRE \\ DES CORNICHES Ȧ MODILLONS (fig. 1)}

D'une façon générale, une corniche est un élément d'architecture de couronnement en saillie : son origine est intimement liée aux toitures et à la nécessité d'habiller le haut des murs pour soutenir la charpente et écarter l'eau de pluie de la construction. L'eau arrivant au bas du toit peut tomber directement au sol, ou être recueillie dans des chéneaux, puis évacuée par des gargouilles. Lorsque l'eau tombe directement, la corniche, par sa forme empêche le ruissellement sur le mur : sa partie plafonnante - le soffite - peut être taillée en contrepente ou creusée en gorge pour obtenir en avant un coupelarme contraignant l'eau à tomber en l'empêchant de ruisseler le long des parois verticales : d'où le nom de larmier. Lorsque l'eau ne s'écoule pas directement, elle est recueillie dans un chéneau qui a la forme d'une cuvette avec un rebord extérieur développé la cimaise -- souvent orné et percé de trous d'évacuation munis de gargouilles qui concentrent l'eau et l'écartent des constructions par leur avancée. Le long des bords latéraux des toitures, appelés rives, 
la corniche est rampante selon la pente du toit, et son rôle de rejet d'eau est moins important; elle sert de soutien aux tuiles de rive qui sont munies d'un rebord externe développé plus décoratif que vraiment fonctionnel, appelé aussi cimaise ; n'ayant qu'à conduire l'eau vers le bas du toit et non à l'évacuer, elle ne doit pas comporter de gargouilles. La constitution des ordres architecturaux doriques et ioniques a pétrifié certaines formules. L'architecture décorative a donné aux différents éléments une vie indépendante des contraintes structurelles, par exemple en superposant les ordres. Ainsi, des corniches se rencontrent en dehors du bas des toits, soit pour couronner des murs, soit pour souligner des étages, soit pour suggérer des architectures purement fictives.

Les corniches d'Alésia sont des corniches à modillons, forme très répandue dans l'architecture romaine el indépendante des formules doriques et ioniques; s'il est évident que ce n'est pas sur ce site que sera résolu le problème de l'origine et de l'évolution de cette corniche, parce que les courants de l'architecture n'y sont arrivés qu'amortis, il est cependant nécessaire de décrire dans le détail les fragments que le hasard a laissés, car ils sont le témoignage de la parure architecturale de la «capitale mandubienne".

La corniche est, très souvent, contenue dans une seule assise de pierre: sa décoration complexe organisée d'une façon rigoureuse est le reflet d'une structure tripartite qui peut se décrire ainsi : au bas se trouve un "soubassement" — zone de transition - formé d'une ou plusieurs moulures superposées en saillie les unes par rapport aux autres; ce "soubassement" supporte une suite de modillons ayant la forme de petites consoles; sur ces consoles s'appuie la partie supérieure proéminente. Cette partie supérieure a suivi une évolution complexe puisqu'elle a eu un rôle fonctionnel, celui de supporter la gouttière et servir de rejet d'eau. Ses éléments maintenant confondus sont difficiles à baptiser selon qu'est évoquée la fonction d'origine ou la forme qu'elles revêtent : larmier, cimaise.

Cependant, le décor qui recouvre ces blocs monolithiques ne peut se décrire uniquement en fonction d'une structure résiduelle peut-être oublièe. Par décor, il faut entendre la mouluration qu'elle soit lisse ou ornée. L'important est la succession des profils : une corniche à moulure lisse et une corniche à moulure ornée peuvent appartenir à la même famille si l'emplacement des moulures et les proportions sont les mêmes. Quoi qu'il arrive, quand le sculpteur réalise des moulures ornées, dans une première phase, celles-ci sont lisses. Une des difficul- tés du vocabulaire de description de blocs d'architecture se trouve dans l'amalgame fréquent entre les mots désignant les profils des moulures et ceux du décor : dans l'architecture provinciale, le décor ne sous-entend pas toujours le profil de la moulure lisse dans laquelle il est sculpté1. Le décor est distribué selon trois registres: un registre inférieur et un registre supérieur formés uniquement de moulures horizontales et rectilignes, traités de façon linéaire (talon, doucine, filet, bandeau, quart-de-rond avec leurs décors correspondants : rais de cœur, perles, perles et pirouettes, denticules, oves) - la première moulure du registre inférieur, souvent un talon, est parfois considérée comme le couronnement de la frise -; entre les deux, un registre médian complexe, en trois dimensions avec introduction de volumes où chaque plan dégagé fait l'objet d'un traitement spécial qui évolue d'une façon autonome : l'élément principal cst le modillon autour duquel s'organisent les autres éléments que sont les métopes, la moulure de couronnement et le soffite du larmier.

- Les modillons sont parallélépipédiques ou profilés en console; ils sont lisses ou ornés d'un décor végétal plus ou moins important qui peut même faire complètement disparaître leurs faces latérales; ces dernières peuvent être aussi nues ou ornées d'une volute en $\mathrm{S}$ évoquant la console. Les modillons surgissent d'un large bandeau.

- Les métopes occupent l'espace vertical du bandeau laissé libre entre les modillons: celui-ci peut être orné de motifs décoratifs ou rester libre. Le terme de métope, issu du vocabulaire de la frise dorique, caractérise bien les décors en petits tableaux individualisés. Par extension, et commodité, ce terme sera conservé ici pour désigner cet espace même s'il reste lisse.

- La moulure de couronnement généralement profilée en quart-de-rond, ou en doucine, se trouve au-dessus des modillons et des métopes : c'est une moulure horizontale continue dont le plan est un méandre en $\mathrm{U}$; elle assure la transition entre les parties verticales des modillons et des métopes et la partie horizontale du soffite ${ }^{2}$.

1 Pour ces problèmes voir R. Ginouvìs et R. Martin, Dictionnaire méthodique de l'architecture grecque et romaine, I, matériaux, techniques de constructions, techniques et formes du décor, Coll. de l'École Française de Rome, 84, Paris, 1985 ; Inventaire général des monuments et des richesses artistiques de la France. Principe d'analyse scientifique. Architecture. Mèthodes et vocabulaire, Paris, 1972.

2 Sur la forme de cette moulure, voir P. Gros, Traditions hellénistiques d'Orient dans le décor architectonique des 
- Le soffite du larmier est la partie plafonnante libre entre les modillons; rarement laissé lisse, cet espace est très souvent occupé par un motif : c'est en fait le larmier primitif ${ }^{3}$. Pour cette partie quatre formules existent :

- a, motif saillant sur soffite lisse;

- b, soffite lisse, sans motif;

- c, motif inscrit sur un caisson et ne faisant pas saillie sur le nu primitif du soffite, le cadre et le modelé étant obtenus par surcreusement du champ;

- d, motif inscrit dans un caisson, mais en saillie par rapport au nu primitif : la saillie du relief correspond, en général, à la hauteur de la moulure de couronnement du modillon.

La traduction graphique d'une corniche est une opération complexe, car le dessin doit donner des informations sur la forme, les dimensions, le décor et la modénature qui englobe des éléments linéaires et d'autres encaissés.

La coupe transversale est certainement la figure la plus pertinente, car elle donne le profil : elle doit être choisie de manière à rendre compte de tous les éléments, aussi bien du caisson du larmier, des métopes que des modillons : le trait de coupe doit passer entre les modillons pour pouvoir représenter la face latérale de l'un deux ${ }^{4}$. La vue par-dessous qui

temples romains de Gaule Narbonnaise, Alti del colloquio internazionale sul thema "La Gallia romana", Rome, Accademia Nazionale dei Lincei, 1973, p. 171.

3 Il y a adéquation entre le terme "larmier" et sa fonction dans l'architecture grecque; si le rôle de rejet d'eau tend à disparaître, cependant dans certaines corniches, il existe encore et, à cet égard, la corniche de la Maison Carrée de Nìmes est l'une des plus remarquables: cf. R. Amy et P. Gros, La Maison Carrée de Nîmes, $28^{\mathrm{e}}$ suppl. à Gallia, Paris, Éd. du CNRS, 1979, p. 156 sq., pl. 22 et 79.

4 Une des difficultés réelles du rendu de la coupe tient à la présence du décor. Lorsque les moulures sont lisses, le dessin en représente le profil exact. En revanche, lorsque les moulures sont ornées, l'usage est de faire passer le trait de coupe par les endroits les plus profondément refouillés et non de faire une section selon les règles du dessin technique : le but est de donner le plus d'informations possible sur un seul dessin : aussi le trait de coupe passera-t-il à la jonction de deux perles ou d'une perle et d'une pirouette, entre deux denticules. Il faut reconnaître, cependant, qu'il n'est pas toujours aisé de faire un dessin clair sur un ovolo, un rais de coeur, des palmettes, un fleuron ou un rinceau. Quoi qu'il en soit, s'il est essentiel de faire passer le trait de coupe par les vides, il est indispensable de dessiner aussi ce qui se voit derrière ce trait. Pour chaque décor, la somme ou l'enveloppe des parties en relief donnera le profil de la moulure primitive : si, pour les denticules ou les perles, le profil primitif correspond au premier élément situé derrière le trait de coupe, ce sera l'ensemble des reliefs d'un rinceau qui donnera l'image du profil primitif : celui-ci correspond à la dernière phase de l'épannelage c'est-à-dire à la phase où les moulures sont achevées mais encore lisses. rend compte des dimensions des éléments en largeur et de la répartition du décor, doit obligatoirement accompagner le profil. La vue de face complète heureusement la documentation, mais une photographie peut la remplacer avantageusement.

Sur le Mont-Auxois, les corniches n'ont été trouvées, dans l'état actuel des recherches représentant 80 ans de fouilles, que dans deux zones : dans le centre monumental comprenant théâtre, temple, basilique et forum et au sanctuaire de Moritasgus, à l'extrémité orientale du plateau (fig. 2).

Les carnets de fouilles relatent les trouvailles de ces fragments sous le terme général de corniche sans préciser leur forme ni leur décor; heureusement, quelques photographies permettent des localisations plus précises. Ces conditions imposent donc des réserves sur les attributions. Pour l'exposé, puisque les classements topographiques et chronologiques sont incertains, il a été choisi de les regrouper ici en deux familles selon leurs aspects : les corniches à moulures lisses et les corniches à moulures ornées.

\section{LES CORNICHES À MOULURES LISSES}

Les réserves lapidaires contiennent une vingtaine de fragments qui peuvent être classés en deux groupes : les corniches à modillons parallélépipédiques - très homogènes - et les corniches à modillons en consoles, plus variées.

LES CORNICHES À MODILlONS PARALLÉLÉPIPÉdQUES $^{5}$ (fig. 3 et 4 )

Cette série est représentée par un lot de trois éléments semblables appartenant à un même édifice dont deux (B 123 et B 124) sont conservés avec leurs moulures intactes. Il s'agit d'un bloc d'angle et d'un bloc droit. Ils ont été trouvés dans un ensemble baptisé "monument à double colonnade» où les fouilles se sont déroulées en deux temps. Une première campagne en 1907-1908, a dégagé en surface un ensemble de structures représentant en façade une suite de salles précédées de deux séries parallèles de dés de fondation de portique, d'où le nom de double colonnade; en 1942 et 1943, les fouilles ont été reprises dans l'intention d'explorer en

5 Henner von IIssherg, Konsolengeisa des Ilellenismus und der frühen Kaiserzeit, $24^{\circ}$ suppl. aux Mitteilungen des Deutschen Archäologischen Instituts, Römische Abteilung (RM), Ergänzungsheft, Mayence, 1980. Pour cet auteur, ces corniches à modillons parallélépipédiques sont des Blockkonsollengeisa, p. $95 s q$. 


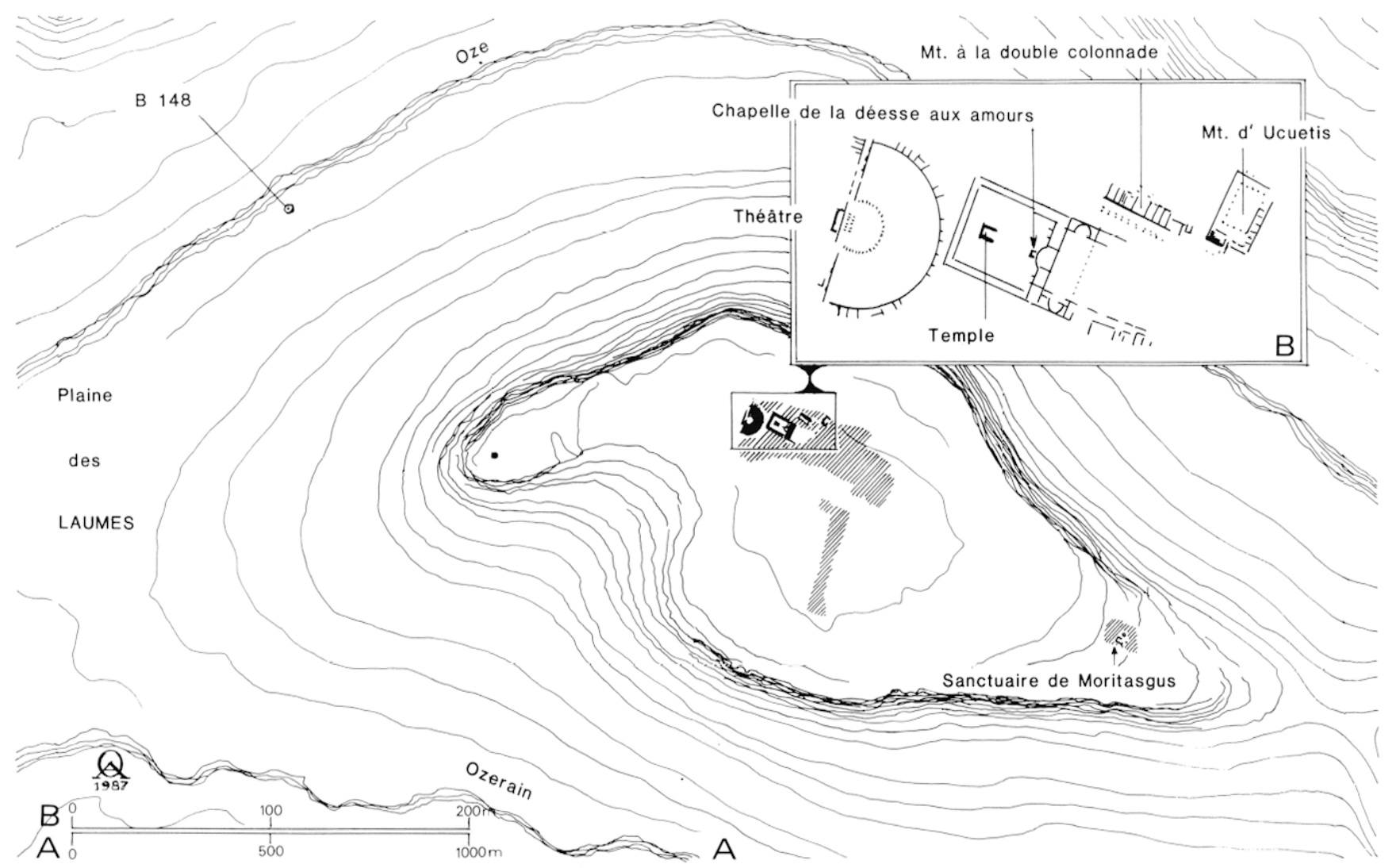

Fig. 2 - A, croquis de localisation des secteurs du Mont-Auxois et de la plaine des Laumes où ont été trouvées les corniches; $\mathrm{B}$, secteur des monuments.

profondeur cet ensemble. C'est à cette occasion qu'ont été mis au jour deux blocs de corniche respectivement en 1942 et en 1943 «dans la zone est $\|^{6}$.

A l'analyse, il apparaît que cet ensemble a subi un remaniement très net : un premier bâtiment précédé d'une colonnade a été remplacé par un deuxième bâtiment de plan analogue mais dont la colonnade a été reculée probablement à l'occasion d'une opération d'urbanisme (fig. 5)?

Où placer les blocs de corniche retrouvés? La présence d'une colonnade régulière incite à restituer une architecture avec un ordre qui lui donne une certaine monumentalité. L'hypothèse la plus vraisemblable serait de placer cette corniche dans un entablement $^{8}$ sur une colonnade. Le bloc d'angle se

6 J. Toutain, Fouilles exécutées à Alésia en 1942 par la Société des Sciences historiques et naturelles de Semur (Côted'Or), Gallia, I, 1943, p. 133-158.

7 E. RABeisen, Les rues d'Alésia, mémoire de Maîtrise dactylographié, université de Dijon, 1972.

8 Il est difficile de suivre Jules Toutain qui, dans l'article cité à la note 6 , voit dans cette corniche de $28 \mathrm{~cm}$ de hauteur un entablement complet : "Elle était couronnée d'un entablement dont nous avons retrouvé un angle : la décoration loge naturellement, ètant donné son lieu de découverte, à l'extrémité orientale du bâtiment. Ce bloc de calcaire oolithique est haut de $28 \mathrm{~cm}$, long de 78 et large de 64. Pour cet ordre de façade, aucun fût de colonne n'a été conservé mais l'entrecolonnement est de 3,80 m. Avec ces seules dimensions, il n'est pas possible de restituer la hauteur de l'ordre, d'autant plus qu'il n'y a aucune information sur la hauteur de l'architrave qui devait même être en bois.

Sur le lit de pose du bloc d'angle, se voit une dépression bordée vers la façade par une zone lisse, qui peut être considérée comme un défoncement d'anathyrose : cet agencement évoque plutôt une architecture de pierre : le bloc B 124, large de $42 \mathrm{~cm}$, ne présente pas cette caractéristique.

Le traitement du lit d'attente est aussi plein d'enseignement: le long des deux faces ornées, la surface présente un glacis large de 15 à $20 \mathrm{~cm}$ et en pente de $20 \%$. Sur le reste de la surface plate et horizontale, une bande retravaillée et piquetée

en est très sobre; entre l'architrave et la corniche, toutes deux représentées par des moulures au profil classique, la frise est remplacée par une ligne de denticules dont les dimensions $(8 \mathrm{~cm} \times 7 \mathrm{~cm} \times 9 \mathrm{~cm}$ de hauteur) s'accordent avec celles des moulures". 

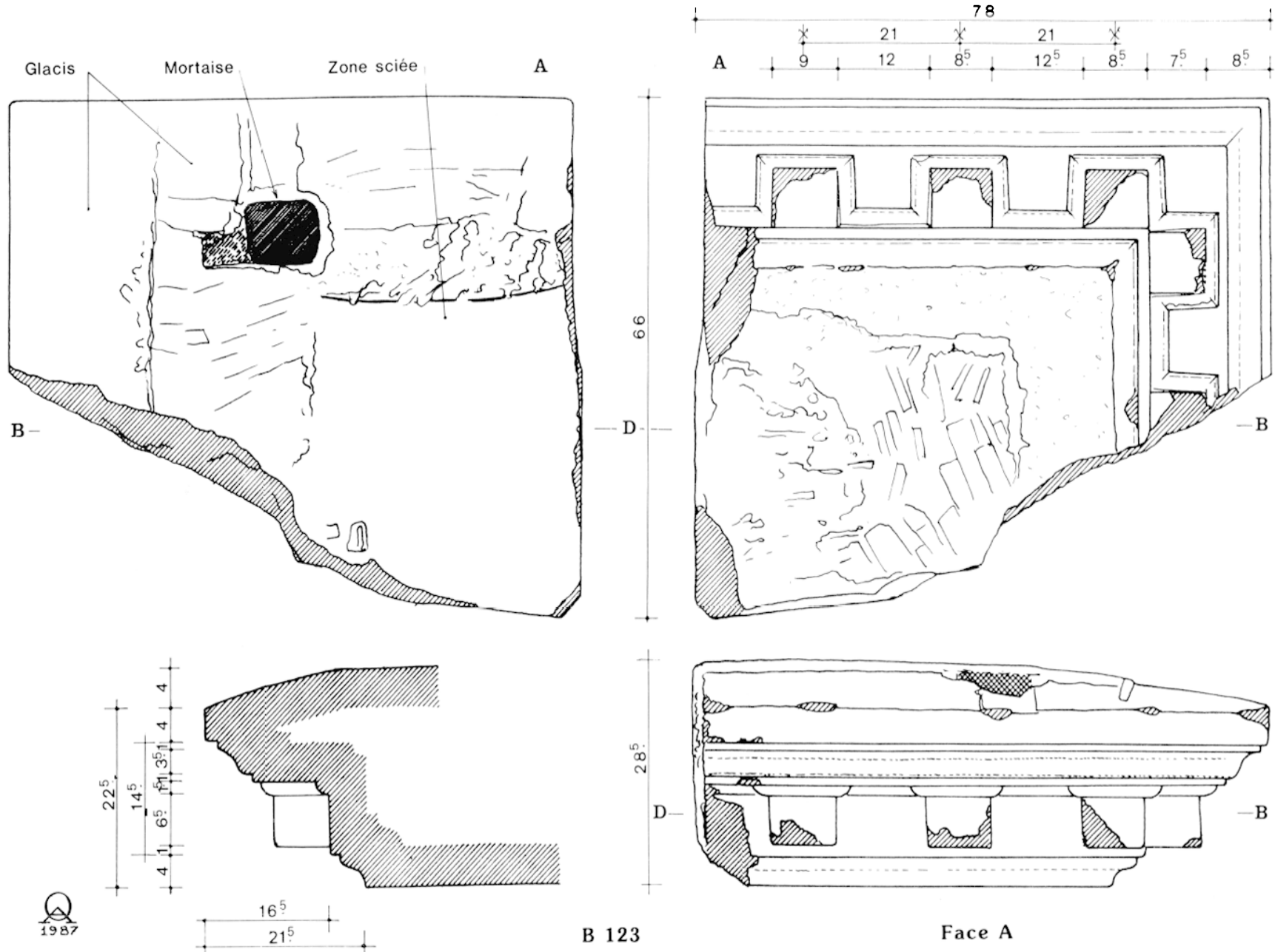

Fig. 3 - Corniche à modillons parallélépipédiques $\mathrm{B} 123$, provenant du monument à la double colonnade. Élévation de la face $\mathrm{A}$, vues de dessus et de dessous, coupe transversale. Echelle 1:10.

encadre une zone lisse ${ }^{9}$. Une grosse mortaise de $6 \mathrm{~cm}$ sur 8 , assez régulière, profonde de $6 \mathrm{~cm}$, est située dans l'angle, à la limite du glacis. Le lit d'attente du deuxième bloc $\mathrm{B} 124$, porte aussi un glacis identique de même pente et de même largeur ; la partie arrière, horizontale, est légèrement surélevée.

- Est-il possible de mettre une toiture audessus de cette corniche? Le glacis longeant la façade est trop étroit pour supporter un chéneau; sa pente est trop faible pour servir d'appui aux éléments de couverture du toit. De plus, il n'aurait aucune utilité s'il était recouvert par une toiture légèrement débordante.

- La corniche d'angle aurait-elle pu être l'extrémité du fronton? Dans ce cas, le lit d'attente

9 La zone lisse de ce lit d'attente a été obtenue par sciage : l'utilisation d'une scie est attestée par la limite courbe de la partie qui se casse en fin de travail et qui est ravalée.

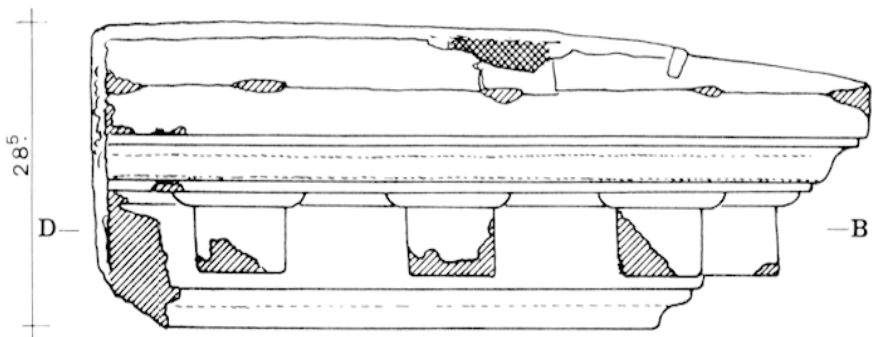

Face A

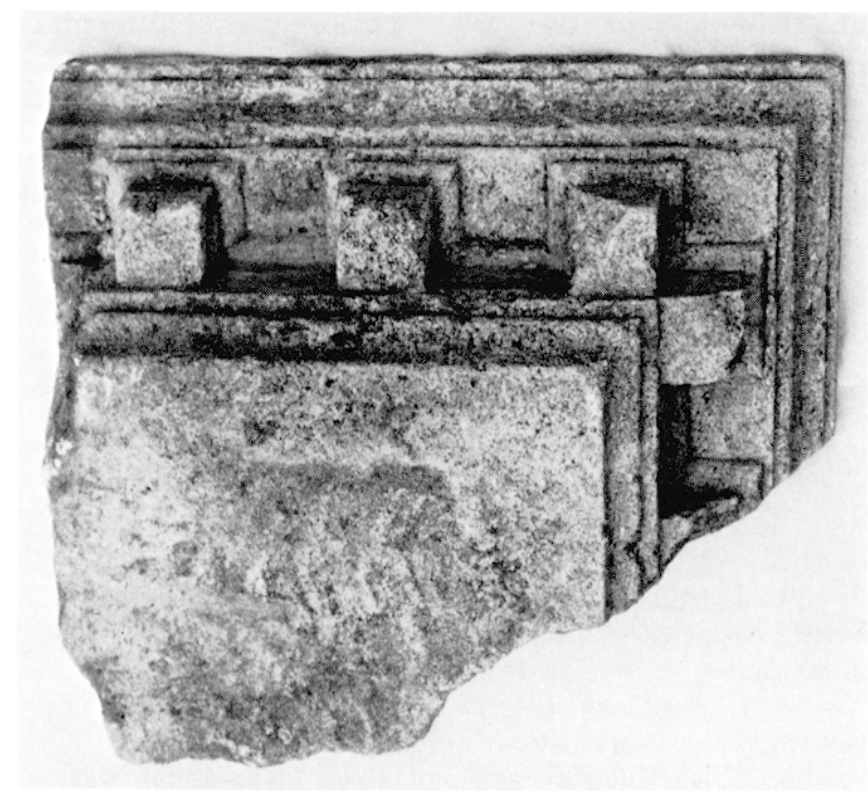

Fig. 4. - Corniche B 123, provenant du monument à double colonnade. 


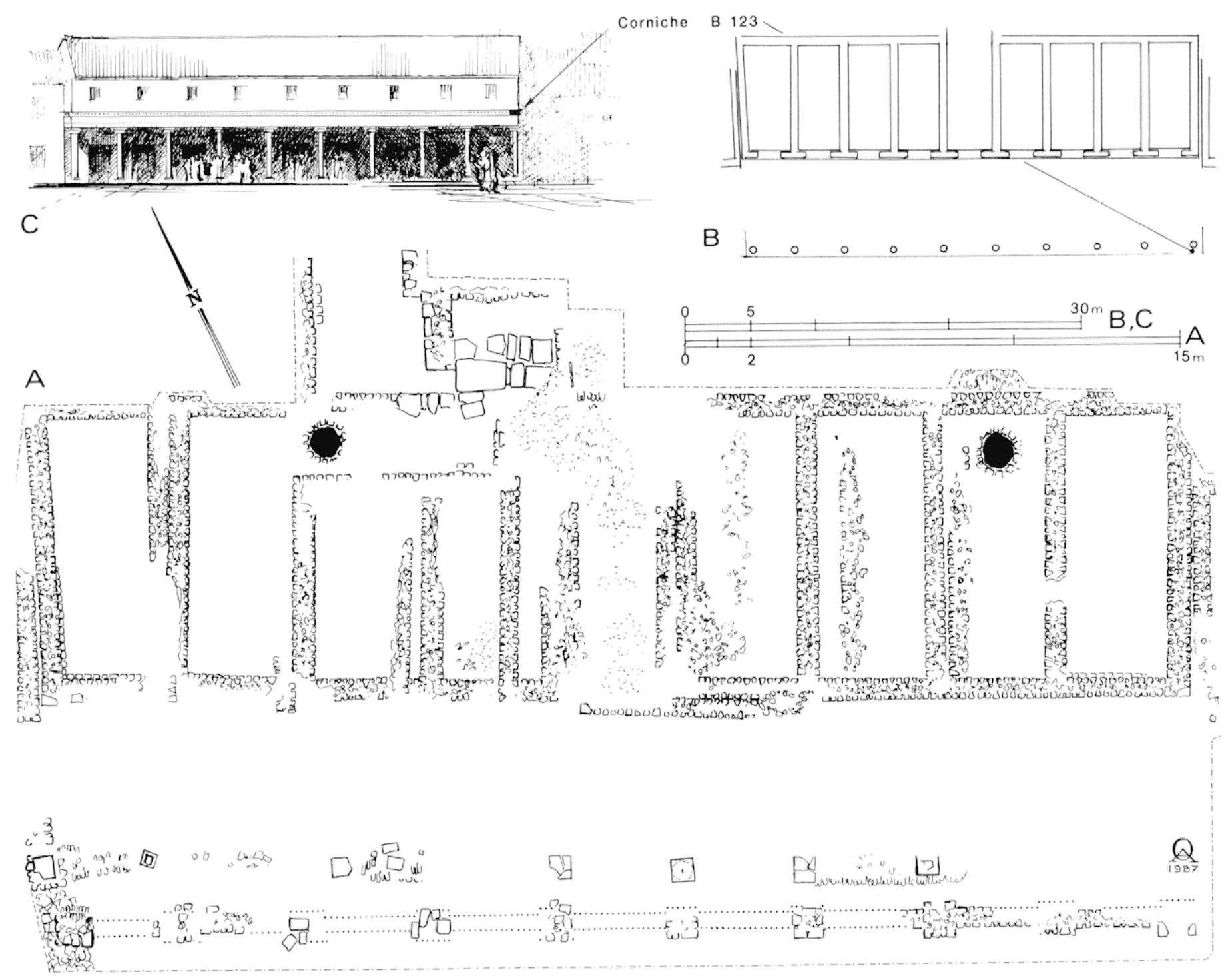

Fig. 5 - Monument à double colonnade. A : plan des vestiges visibles en 1971, échelle 1:200; B : plan de restitution du premier état; $C$ : élévation hypothétique de la façade principale avec un étage sur la colonnade, échelle $1: 500$.

aurait été aménagé pour permettre l'ajustement exact du rampant et le glacis n'aurait existé que sur un côté. Force est d'admettre que sur ce bloc venait s'appuyer une structure verticale : il apparait très vraisemblable qu'un étage était aménagé au-dessus de cette galerie. Les éléments manquent pour déterminer la nature de cet étage : il pouvait être en pierre ou en pan de bois; la grosse mortaise de $6 \mathrm{~cm}$ sur $8 \mathrm{du}$ bloc d'angle incite à penser qu'elle servait à l'ancrage d'une structure en bois. L'examen de ce bloc de corniche permet donc d'évoquer à proximité de l'ensemble monumental, la présence d'un bâtiment avec galerie et étage (fig. $5, \mathrm{C}$ ).

- A quel état du monument faut-il attribuer cette organisation? Au premier état ou au remaniement? Les renseignements stratigraphiques sont très faibles mais la date de la découverte, en 1942-1943, quand les fouilleurs dégageaient les couches jusqu'au sol naturel, permet de dire que les blocs ont été trouvés dans les couches profondes et pourraient donc appartenir au premier état.

Il reste que ces indications demeurent aléatoires, mais l'examen du décor lui-même peut aussi donner des informations. Il s'agit d'une corniche à modillons presque cubiques (hauteur : $6,5 \mathrm{~cm}$; largeur : $8,5 \mathrm{~cm}$, profondeur : $7,5 \mathrm{~cm}$ ) dont les moulures sont lisses. Le registre inférieur est formé d'un seul talon; le registre médian, de modillons distants de $12 \mathrm{~cm}$; les métopes et le soffite sont dépourvus de décor et la moulure de couronnement, proche du quart-de-rond; le registre supérieur se réduit à une doucine entre deux filets, couronnée par un bandeau. 
Le rapport de la hauteur sur la saillie est de 1,04 ${ }^{10}$.

Si les corniches à modillons parallélépipédiques sont fréquentes et bien connues en Italie au $\mathrm{I}^{\text {er }} \mathrm{s}$. avant notre ère ${ }^{11}$, elles semblent beaucoup plus rares en Gaule. Dans l'état actuel des publications, celle qui couronne l'attique de l'arc de Germanicus à Saintes peut donner un repère chronologique ${ }^{12}$, ainsi que celle du mausolée de l'Ile du Comte (dit de Vallabrègues) près de Beaucaire (Gard) ${ }^{13}$. Plus près d'Alésia, cette formule est utilisée pour la décoration de l'entablement inférieur de la porte Saint-André d'Autun (Saône-et-Loire)14 ${ }^{\mathbf{1 4}}$ cet entablement appartient à l'étage qui n'a pas été remanié dans l'Antiquité tardive et qui selon toute vraisemblance date, comme la porte d'Arroux, de la création de l'enceinte, à l'époque augustéenne.

En l'absence d'inventaire, il n'est pas possible de savoir jusqu'à quelle époque cette forme s'est maintenue en Gaule : quoi qu'il en soit, il semble que ce décor a pratiquement cessé d'être utilisé au-delà du premier quart du ${ }^{\text {er }} \mathrm{s}$. de notre ère.

En confrontant cette analyse avec les observations faites sur la chronologie de l'ensemble, il est donc raisonnable de penser que cette corniche appartenait à la première construction de ce qui est appelé "monument à double colonnade». Dans sa version initiale, ce monument très régulier est formé de neuf salles identiques aux sols soignés; à chaque mur de refend correspond une colonne; les fondations même de cette colonnade sont assez élaborées, chaque dé de maçonnerie étant relié par un muret enterré assurant la cohésion de l'ensemble. La

10 P. Gros, Entablements modillonnaires d'Afrique au ${ }_{I^{e}} \mathrm{~s}$. après J.-C. (à propos de la corniche des temples du forum de Rougga), $R M, 85,1978$, p. $459-476$, donne à la note 6 de la page 462 des informations sur ce rapport $\mathrm{H} / \mathrm{L}$.

11 IIEnNer von Hesberg, op. cit.; - ID. Lo sviluppo dell'ordine corinzio in età tardo-repubblicana in : L'art décoralif à Rome à la fin de la République et au début du Principal, Rome, 1979, EFR, 1981, p. 19-53.

12 L. MAUrin, Saintes antique des origines à la fin du $v^{r}$ siècle après Jésus-Christ, Saintes, 1978, p. 71-81. D. Tardy me signale que le musée de Saintes possède deux séries importantes de corniches de ce type, droites et courbes.

13 A. Roth-Congès date ce monument entre la première et deuxième décade du $\mathrm{I}^{\mathrm{er}} \mathrm{s}$. avant $J .-\mathrm{C}$. : J.-C. Bessac, M. Christol, J.-L. Fiches, Y. Gasco, M. Janon, A. Michelozzi, C. Raynaud, A. Roth-Congtis, D. Terrer, Ugernum, Beaucaire et le Beaucairois à l'époque romaine, II, ARALO, Cahier no 16, 1987, p. 66, 86.

14 P.-M. Duval et P. Quoniam, Relevés inédits des monuments antiques d'Autun (Saône-et-Loire), Gallia, XXI, 1963 , p. 154-189, spécialement fig. 14,15 et 16 ; M. Pinfette et A. Rebourg, Aulun, (coll. des Guides archéologiques de la France), Paris, 1986, p. 64-66. destination de ce bâtiment n'est pas assurée : Toutain a pensé à des thermes parce qu'à l'arrière se déploie une série de constructions complexes avec hypocauste, N. Zink penche plutôt pour une structure à caractère commercial ${ }^{15}$.

Il faut, de toute façon, souligner le caractère relativement monumental de cette façade qui devait être un élément constitutif du centre d'Alésia à un moment où la basilique et le portique entourant le temple n'étaient pas encore construits.

Dans une bourgade gallo-romaine, la formule d'un bâtiment à étage avec galerie au rez-dechaussée en bordure d'une rue ou d'une place devrait être envisagée plus fréquemment lorsque les vestiges présentent une série de points d'appui isolés le long d'une construction. Les restitutions qui proposent de placer le long des rues des bâtiments précédés d'un passage couvert avec une toiture en appentis sur des colonnes ou des poteaux de bois devraient être soigneusement justifiées ; cette formule architecturale est, en effet, rare et coûteuse pour un simple usage de "parapluie" alors que la formule de l'auvent en porte-à-faux existe et est bien attestée là où les fouilles ont dégagé des vestiges atteignant les étages comme à Herculanum ${ }^{16}$. En revanche, les bâtiments à étage sur galerie ont eu une longue histoire architecturale depuis l'Antiquité jusqu'aux périodes les plus récentes qu'il ne faudrait pas oublier de prendre en compte ${ }^{17}$.

\section{LES CORNICHES Ȧ MODILLONS EN CONSOI.F}

Les fragments retrouvés peuvent être regroupés en deux ensembles, l'un apparenté au théâtre, l'autre au sanctuaire de Moritasgus.

- a. Au cours des fouilles récentes du théâtre ${ }^{18}$, ont été mis au jour plusieurs fragments de

$15 \mathrm{~N}$. ZıNK, Le monument à double colonnade et ses abords, mémoire de Maîtrise dactylographié, université de Dijon, 1971, conservé à la direction des fouilles d'Alésia.

16 A. Maruri, Ercolano, I novi scavi 1927-1958, Rome, 1958, par exemple pl. XII, XIX (casa del Tramezzo di Legno), XXII, XXVI, XXXVII (casa del telaio).

17 R. Martin, Formation et développement de l'habitat urbain en Gaule romaine, in: Thème de recherches sur les villes antiques d'Occident, colloque de Strasbourg, 1971, Paris, 1977, p. 173-184; - Chr. Goudinfau, in : La France urbaine, sous la direction de G. Dubr, I, p. $296 s q . ;-$ R. Hanoune, La maison romaine, nouveautés, in : A pamée de Syrie, colloque de Bruxelles, 1980, Fouilles d'A pamée de Syrie, Miscellanea, 13 , Bruxelles, 1984, p. 431-446; - Forum el plaza mayor dans le Monde hispanique, colloque inter-disciplinaire, Casa de Velazquez, Madrid, 28 octobre 1976, Paris, 1978.

18 A. Olivier et E. Rabeisen, Le théâtre, sondages à l'angle Nord-Ouest de la façade, Tour de l'Orle d'Or (TOO), 1984, 1, p. 12-14, fig. 

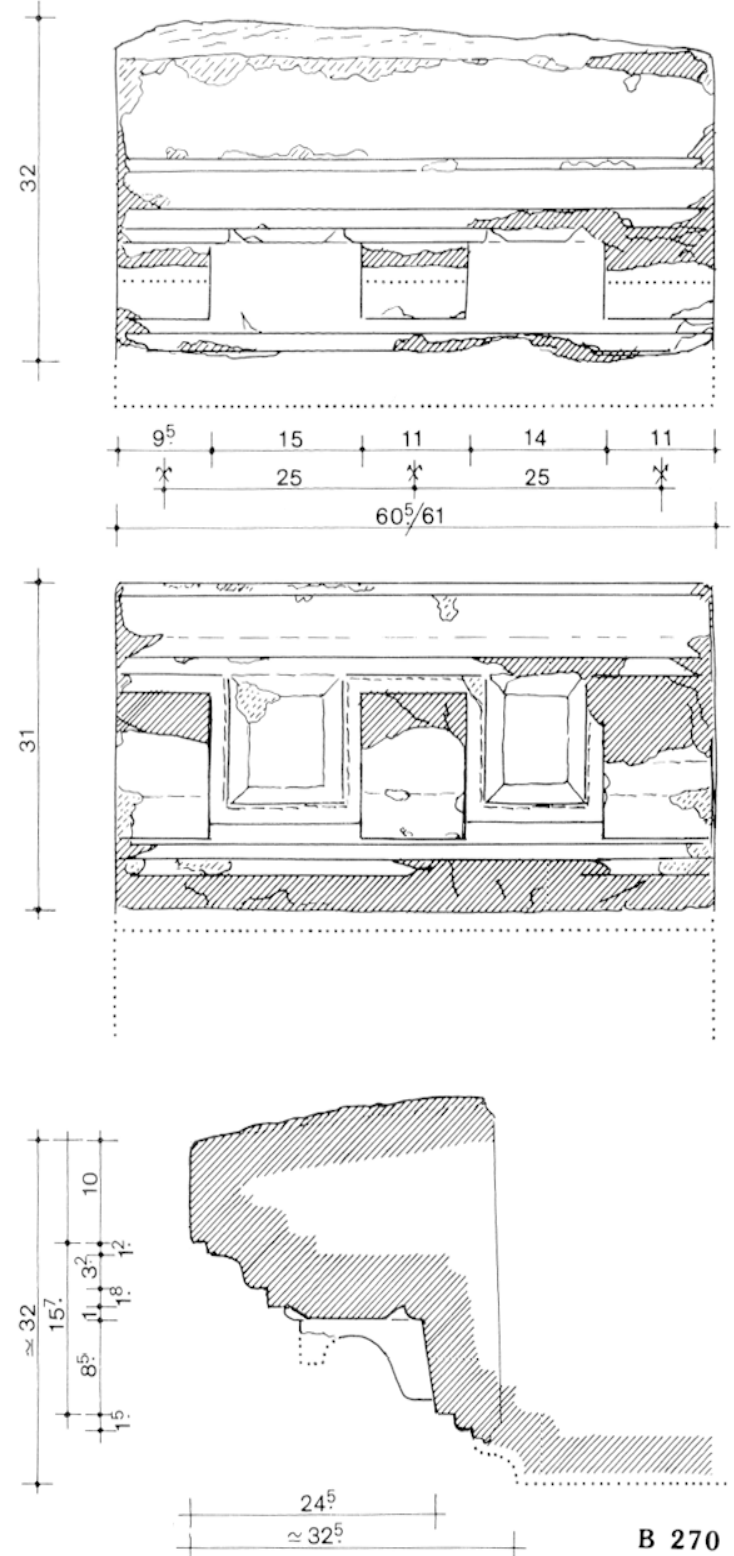

Fig. 6 - Corniche modillonnaire à moulures lisses B 270, provenant du théâtre. Vues de face et de dessous, coupe. Échelle $1: 10$.

corniches et parmi ceux-ci une corniche presque complète, B 270 (fig. 6 et 7). Les collections lapidaires d'Alésia possédaient déjà plusieurs éléments trouvćs dans les fouilles antérieures sans localisation, qui ont pu être rapprochés de ce type. C'est dans les tranchées le long de la façade que sont mentionnées les découvertes d'éléments de corniche. Les débris sont très fragmentés car il semble bien qu'il y ait eu un gros travail de récupération de matériaux à cet endroit : tout l'arrière du bloc B 270 a été scié et seule est conservée la face décorée probablement inutilisable: les récupérateurs ont coupé au plus juste dans leur intérêt, emportant aussi la moulure inférieure.

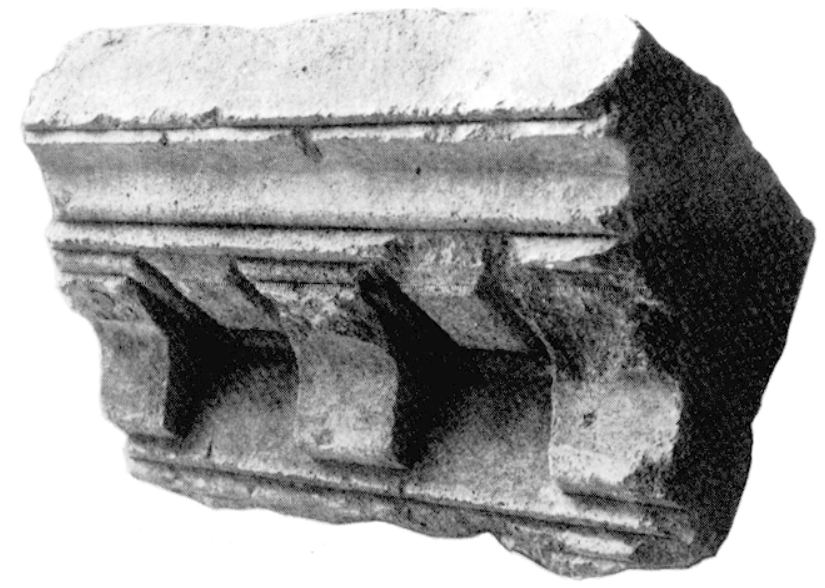

Fig. 7 - Corniche B 270, provenant du théâtre.

Malheureusement, il ne reste ni lit d'attente ni lit de pose pour donner des indications sur la destination de ce bloc. Quant à sa restitution à sa place d'origine, elle pose un problème difficile à résoudre car les indices intéressant la décoration architecturale du théâtre sont très ténus. La "façade» en moellons présente un rythme de pilastres en grand appareil; d'autre part, les fondations du bâtiment de scène comportent un soubassement fait de grands blocs bien ajustés avec des repères de pose, probablement pour une superstructure à caractère monumental. Parmi les éléments d'architecture retrouvés à ce jour, figurent des fragments de chapiteaux corinthiens et composites; de plus, les différents fragments de corniches n'ont pas tous exactement le même module ${ }^{19}$. Cependant, dans l'état actuel des recherches, ces indices ne sont pas suffisants pour proposer une restitution car il pouvait y avoir une décoration en plusieurs endroits.

En revanche, le bloc B 270 donne des indications sur le style. Ce bloc de calcaire oolithique, complet en largeur avec ses deux cadres d'anathyrose, mesure $61 \mathrm{~cm}$; sa hauteur et sa profondeur conservées sont respectivement de 33 et $31 \mathrm{~cm}$. Du registre inférieur abîmé, il ne reste qu'un filet droit et l'amorce d'une moulure, sans doute le talon inférieur. Au registre médian, trois modillons en console, larges de 10,5 à $11 \mathrm{~cm}$ et espacés de 14 à $15 \mathrm{~cm}$ avec retombée antérieure verticale; les retombées, ici toutes cassées, se restituent à partir des fragments voisins retrouvés en même temps; les

19 Le bloc B 122 conservé dans les réserves ayant des modillons de $8 \mathrm{~cm}$ distants de $13 \mathrm{~cm}$ (entraxe : $21 \mathrm{~cm}$ ) a été attribué au théâtre gràce à un dessin anonyme ancien à l'échelle de $1 / 2$ dessiné au crayon sur calque qui porte la mention "fragment de corniche trouvé dans le théâtre". 
métopes sont lisses; la moulure de couronnement proche du quart-de-rond; le soffite enfin est décoré en relief, d'un prisme en forme de tronc de pyramide très aplati de $1 \mathrm{~cm}$ de saillie, correspondant à la hauteur de la moulure de couronnement du modillon. Au registre supérieur, une doucine entre deux filets, surmontée d'un bandeau en saillie; ce qui reste du lit d'attente est en glacis.

Les données récentes de la fouille placent la construction du théâtre dans la seconde moitié du $\mathrm{I}^{\text {er }} \mathrm{s}$. de notre ère, certainement après le règne de Claude $^{20}$. Les corniches de cette forme sont très employées en Gaule: elles figurent sur l'arc de Germanicus à Saintes (Charente-Maritime); régionalement, elles décorent le théâtre de Mandeure (Doubs) ${ }^{21}$; beaucoup sont conservées dans les réserves lapidaires des musées, mais peu sont publiées ${ }^{22}$.

- b. A Alésia mème, un autre ensemble a dû recevoir aussi une décoration du même ordre : il s'agit du sanctuaire thermal de Moritasgus situe sur l'autre extrémité du Mont-Auxois, au lieu-dit La Croix-Saint-Charles. Le commandant Espérandieu a relaté dans les fouilles, la découverte d'un bloc de corniche complet, B 382, mais en deux morceaux, qu'il jugeait remployé; la description qu'il en donne est succincte ${ }^{23}$. Le bloc étant resté en place depuis la date de fouille, la partie supérieure a malheureusement disparu et il n'en reste que la moitié inférieure. Cependant, la restitution ne pose pas de problème grâce à une photographie prise au moment de la découverte. C'est ainsi qu'il est possible de rapprocher de cet élément d'autres fragments sans provenance conservés au musée.

Ces corniches appartiennent au même type que celui qui vient d'être décrit, mais sont d'un module plus important. Dans son état actuel, cette corniche B 382 en calcaire oolithique, large de $98 \mathrm{~cm}$, ayant à ses deux faces de joint un cadre d'anathyrose et

20 A. Olivifr et E. Rabisen, Le théâtre, sondages à l'angle . Vord-Ouest de la façade en $1984, T O O, 1985,1$, p. 1319.

21 Y. Jrannin, Le théâtre romain de Mandeure, le problème de sa décoration architecturale, Archéologia, 62, 1973 , p. 39-48, fig. 44 et 47 . Les corniches ont des modillons larges de $12 \mathrm{~cm}$ et distants de $19 \mathrm{~cm}$ (entraxe $31 \mathrm{~cm}$ ) : les cotes ont été déduites d'un document de l'auteur que je remercie bien vivement.

22 L. Armand-Calliat, La décoration des monuments antiques de Châlon-sur-Saône in : Ilommage à Albert Grenier, (Coll. Latomus, LVIII), Bruxelles, 1962, I, p. 145-151, fig. 10.

23 E. Espérandiev, Fouilles de la Croix-Saint-Charles au Mont-Auxois, (2 rapport), Mémoires de la Commission des Antiquités du département de la Côte-d'Or, (MCA Côte-d'Or), 1912 , pl. IV. possédant une mortaise de bardage au lit de pose, est profonde de $1 \mathrm{~m}$ pour une hauteur maximum de $24 \mathrm{~cm}$.

Le registre inférieur est réduit à un seul talon; au registre médian, les modillons de $13 \mathrm{~cm}$ de largeur sont distants de $17 \mathrm{~cm}$ (entraxe : $30 \mathrm{~cm}$ ); la moulure de couronnement est proche du quart-de-rond ${ }^{24}$. Les métopes sont lisses et au soffite se trouve le décor prismatique en relief. Le registre supérieur est composé d'une doucine entre deux filets surmontés d'un bandeau lisse.

Il est possible de rapprocher cette corniche d'autres fragments : B 86 et B 87 sont deux corniches complètes en largeur, mais dont le registre inférieur a disparu ainsi que la partie arrière (fig. 8 et 9). Sur les lits d'attente se voient des zones en relief de 5 à $7 \mathrm{~cm}$ qui occupent la moitié de la surface conservée, réduisant la partie plane à une bande de $8 \mathrm{~cm}$ en façade. Les modillons larges de $16 \mathrm{~cm}$, sont distants de 17 à $18 \mathrm{~cm}$ (entraxe : 33$34 \mathrm{~cm}$ ); les soffites relativement étroits sont ornés de prismes dont le plan est rectangulaire ${ }^{25}$.

Enfin, une autre corniche assez volumineuse, mais très abîmée, $\mathrm{B} 337$, déposée dans les réserves du musée Alésia, possède des modillons de $18 \mathrm{~cm}$ de largeur distants de $19 \mathrm{~cm}$ ce qui donne un entraxe de $37 \mathrm{~cm}$.

Ces indications de dimensions de modillons et d'entraxes sont-elles suffisantes pour dire qu'ils proviennent de plusieurs monuments différents ou simplement de différcntes parties d'un même monument? Le décor architectural romain en général, accepte des variations dans le rythme de ses ornements suffisamment grandes pour rendre impos-

24 En fait, cette moulure est formée de deux surfaces horizontale et verticale reliées par une petite surface arrondie : les tailleurs de pierre prennent, semble-t-il, quelques libertés avec les modèles de la grande architecture de marbre lorsqu'ils doivent orner des monuments de moindre importance. C'est peut-être aussi la dureté de la pierre qui joue un rôle : en effet, les jeunes tailleurs de pierre qui ont taillé les éléments manquants de l'entablement dont il sera question plus loin, affirment préférer travailler la pierre dure, plutôt que la pierre trop tendre : cette dernière favorise le travail rapide pour ne pas dire bâclé.

25 La surface du soffite est limitée sur trois côtés par la moulure de couronnement des modillons. Lorsqu'il est orné, le fleuron est lui-même sculpté dans un caisson : pour que ce caisson soit de plan carré, il faut que la distance des modillons entre eux soit sensiblement supérieure à leur profondeur. Cette exigence n'étant pas toujours respectée, les caissons des fleurons sont très souvent plus étroits que profonds : il en est de mème lorsque le bloc est resté à l'état de mouluration lisse et que le soffite est occupé par un prisme troncopyramidal. 

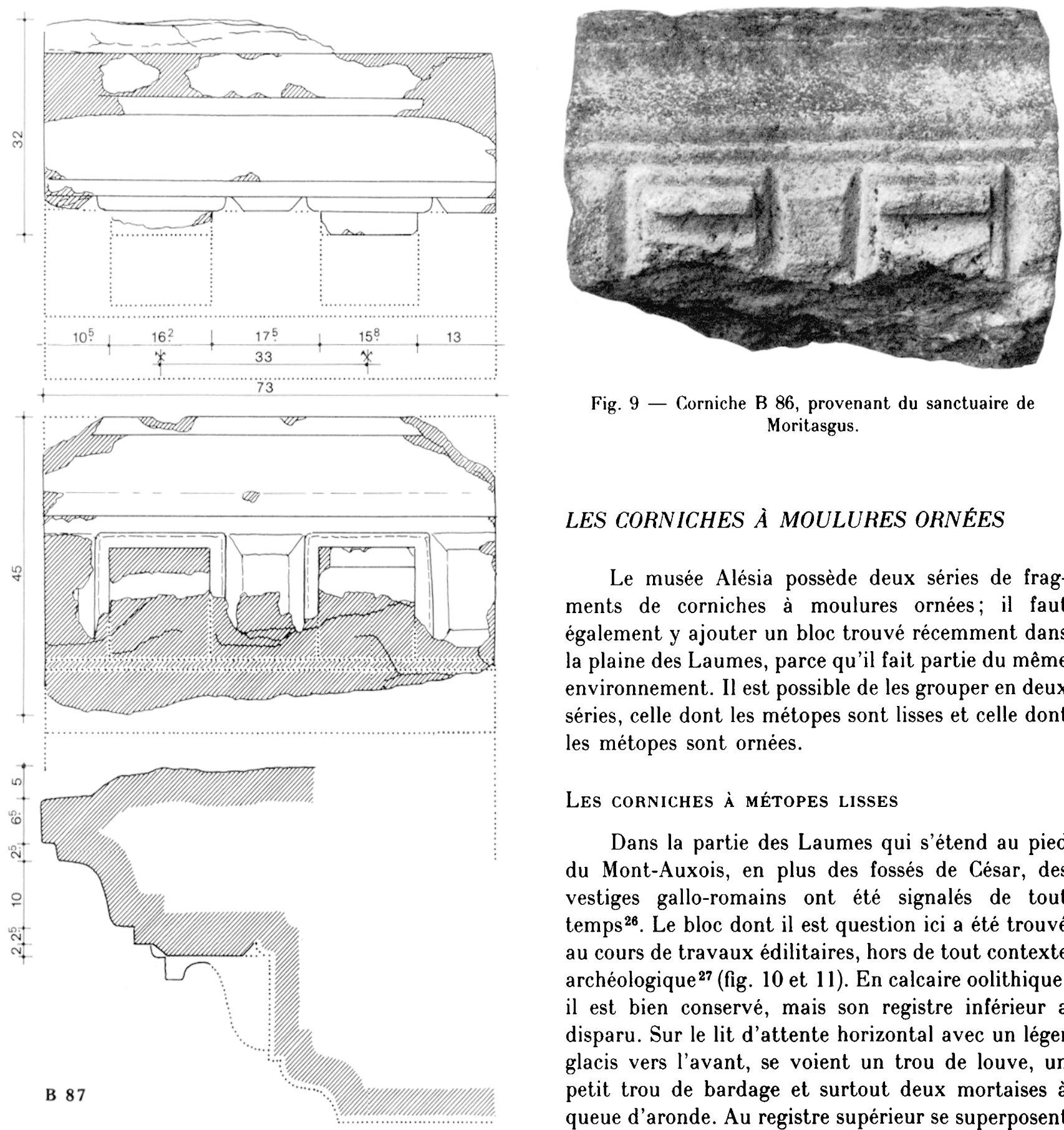

Fig. 9 - Corniche B 86 , provenant du sanctuaire de Moritasgus.

\section{LES CORNICHES À MOULURES ORNÉES}

Le musée Alésia possède deux séries de fragments de corniches à moulures ornées; il faut également y ajouter un bloc trouvé récemment dans la plaine des Laumes, parce qu'il fait partie du mème environnement. Il est possible de les grouper en deux séries, celle dont les métopes sont lisses et celle dont les métopes sont ornées.

\section{LES CORNICHES À MÉTOPES LISSES}

Dans la partie des Laumes qui s'étend au pied du Mont-Auxois, en plus des fossés de César, des vestiges gallo-romains ont été signalés de tout temps ${ }^{26}$. Le bloc dont il est question ici a été trouvé au cours de travaux édilitaires, hors de tout contexte archéologique $^{27}$ (fig. 10 et 11). En calcaire oolithique, il est bien conservé, mais son registre inférieur a disparu. Sur le lit d'attente horizontal avec un léger glacis vers l'avant, se voient un trou de louve, un petit trou de bardage et surtout deux mortaises à queue d'aronde. Au registre supérieur se superposent un filet, une doucine et un bandeau. Le filet et le bandeau sont lisses, la doucine ornée d'un rais de cœur. L'épannelage de ce registre est identique à celui décrit précédemment (une doucine entre deux filets), mais le relief du décor de rais de cœur efface le

sible la réponse à cette question, ou du moins pour laisser ouverte la possibilité de l'appartenance à un seul et même édifice.

Les corniches lisses à modillons en console sont assez répandues : il serait souhaitable pour retracer leur évolution qu'elles apparaissent plus souvent dans les comptes rendus de découvertes.

26 Bulletin de la Socièté des Sciences de Semur (BSSS), 1885 , p. 71, 75, 93, 97-100; - R. Goguey, De l'aviation à l'archéologie, Paris, èd. Technip, 1968, spécialement p. 122 sq.

27 Cette corniche a fait l'objet d'une information accompagnant une planche très complète établie par le Bureau d'Architecture antique de Dijon, CNRS, dans TOO, 1982, 1, p. 12 et 13. 

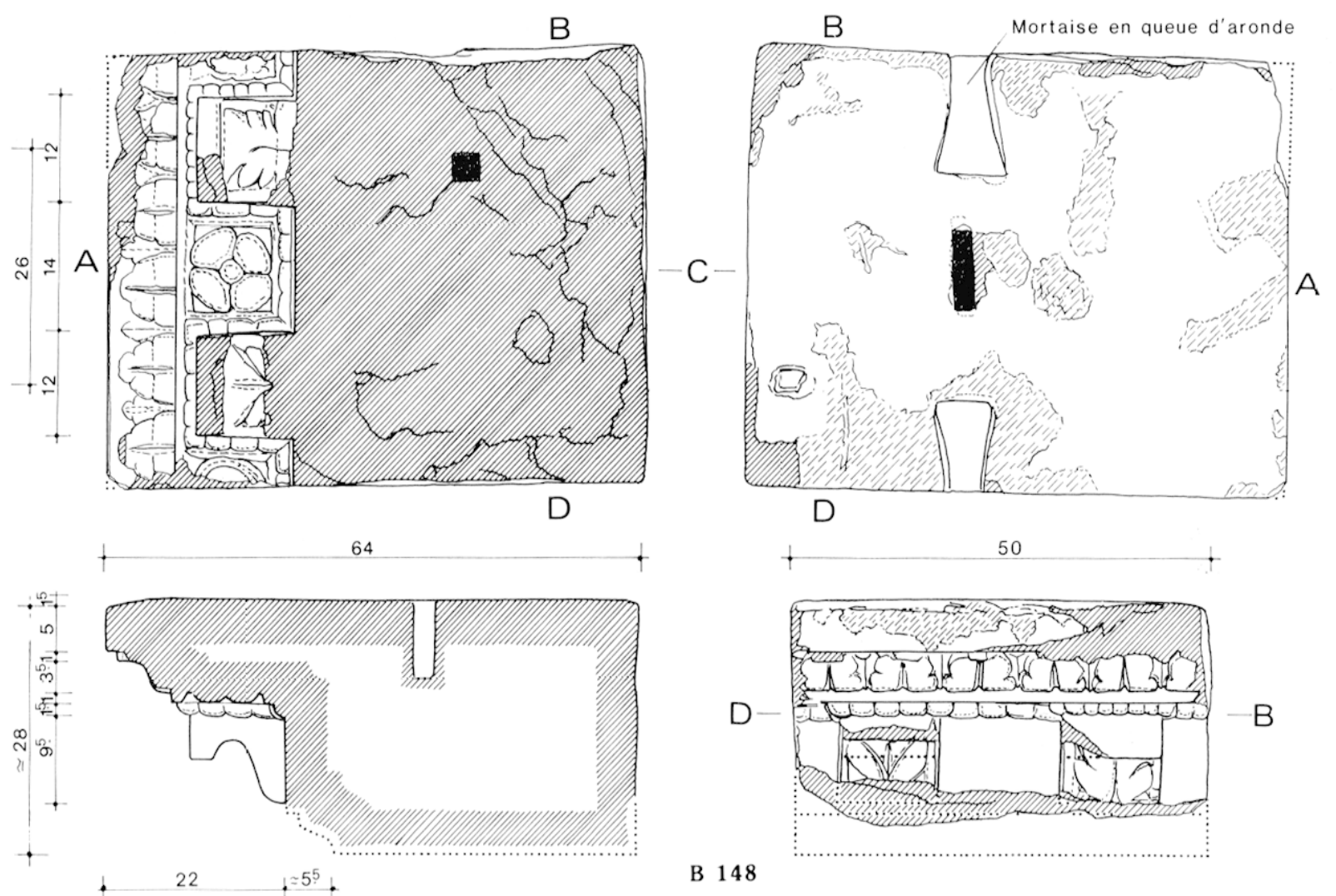

Fig. 10 - Corniche modillonnaire à moulures ornées et métopes lisses B 1.48, provenant de la plaine des Laumes. Vues de face, de dessus et de dessous, coupe. Echelle $1: 10$.

filet supérieur qui correspond à l'épaisseur même des feuilles du décor. $A$ u registre médian, les modillons larges de $12 \mathrm{~cm}$ sont distants de 14 à $15 \mathrm{~cm}$ (entraxe : $26-27 \mathrm{~cm}$ ). Leur profil en $S$ assez cambré se termine par une lourde retombée verticale laissée libre. La feuille qui orne leur face est strictement contenue dans un cadre latéral clairement souligné d'un petit filet : la découpe des faces latérales lisses correspond donc exactement au profil du modillon; la moulure de couronnement profilée en quart-derond est formée d'une suite de perles irrégulières; les métopes sont lisses alors que les soffites sont ornés de motifs non saillants dans un caisson, obtenus par un surcreusement du champ : c'est un fleuron à quatre pétales et bouton central.

Dans l'état actuel des publications, les comparaisons ne sont pas nombreuses en Gaule. Cependant, cette corniche présente quelques similitudes avec celle du péribole des temples géminés de Glanum sur les points suivants ${ }^{28}$ : la superposition des moulures, les métopes lisses, les soffites décorés de motifs non

28 P. Gros, Les temples géminés de Glanum, ètude préliminaire, Revue archéologique de Narbonnaise (RAN), XIV, 1981, p. 125-158.

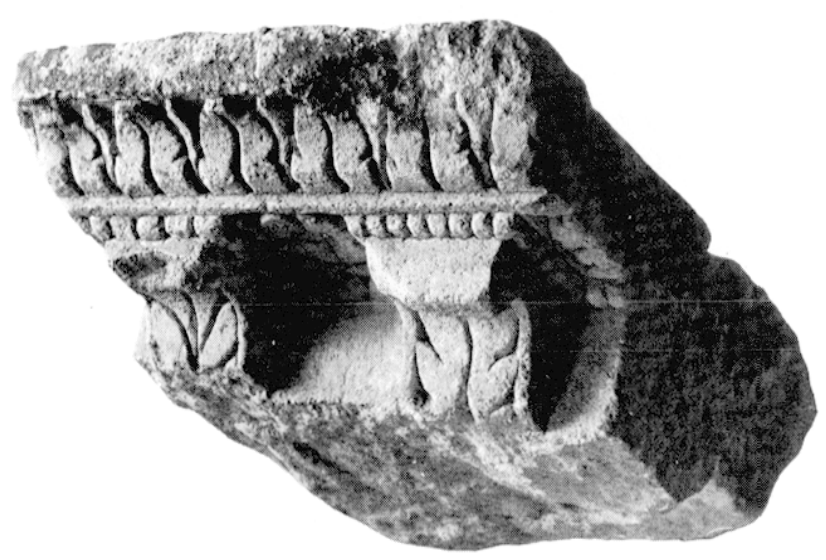

Fig. 11 -- Corniche 13 148, provenant de la plaine des Laumes.

saillants, la feuille du modillon bien contenue dans son cadre, la moulure de couronnement profilee en quart-de-rond (des perles à Alésia, des oves à Glanum).

Cette comparaison n'implique pas de filiation, mais donne peut-ètre une indication chronologique; les exemples régionaux sont, en effet, trop peu étudiés pour constituer des séries. Cependant, il convient de souligner la présence de queues d'aronde 
qui sont une forme de scellement traditionnellement considérée comme précoce et qui s'observe, par exemple, sur la porte d'Arroux d'Autun ${ }^{29}$.

\section{L.ES CORNICHES A MÉTOPES ORNÉES}

Dans l'architecture gallo-romaine, les métopes des corniches à modillons sont souvent ornées avec beaucoup de fantaisie et de variété : ce n'est pas le cas à Alésia qui ne possède que deux exemples de ce type avec un décor très sobre.

\section{PREMIER EXEMPLE}

Le musée Alésia conserve une série de petits fragments de corniche bien décourageants, a priori, quoique de facture soignée (fig. 12 à 14). L'examen attentif de cette quinzaine d'éléments a permis de mettre en lumière certaines caractéristiques qui ont conduit à des hypothèses inattendues. Si certains fragments sont identifiables facilement, comme des portions de modillons et de soffites, les moulures sont plus difficiles à mettre à leur place exacte. L'examen des faces non décorées des joints latéraux ainsi que des lits de pose et d'attente, a été déterminant pour la restitution. Sur le bloc B 63 figurent les éléments des registres médians et supérieurs; le bloc $\mathrm{B} 341$ qui possède une amorce de lit de pose, donne une certitude pour le registre inférieur. Bien qu'aucun fragment ne se recolle à un autre, il est néanmoins possible de restituer, avec une très grande certitude, une corniche de $60 \mathrm{~cm}$ de hauteur environ en juxtaposant les différents éléments dans leurs registres respectifs.

Le registre inférieur est un rais de cœur profilé en talon.

Au registre médian, les modillons en console sont ornés de feuilles à sept lobes profondément découpés qui occupent toute la façade laissant leurs faces latérales lisses. Les métopes sont ornées d'un motif très sobre : deux rainures verticales profilées en $\mathrm{V}$ séparent trois feuilles ou godrons plats très simples (ce décor n'est connu que par un seul fragment, B 384, qui ne présente lui-même qu'une petite métope incomplète; cependant, il est. tout à fait assuré et la corniche de la chapelle de «la déesse

29 Grâce à l'amabilitè de l'architecte en chef des Monuments historiques de Saône-et-Loire et la compréhension de l'entreprise, il a été possible de profiter des échafaudages et d'observer les parties hautes de cette porte : tous les blocs supérieurs sont liés deux à deux par des queues d'aronde. Pour la date de ce type de scellement cf. G. Lugi.I, La technica edilizia romana con particolare riguardo a Roma e Lazio, Rome, 1957, I, p. 236. aux amours" analysée plus loin, en apporte la confirmation).

La moulure de couronnement profilée en quartde-rond est ornée de grosses perles irrégulières. Au soffite, un fleuron à quatre pétales et bouton central fait saillie sur un cadre rectangulaire jusqu'au bas de la moulure de couronnement.

Le registre supérieur est composé d'une grande doucine ornèe d'un rais de cœur fait de larges feuilles lisses, entre deux filets, sous un bandeau plat.

Un seul doute subsiste : en effet, au registre inférieur le bloc B 341 possède au-dessus du talon et du filet qui lui est superposé, l'amorce d'une moulure difficile à interpréter : il ne semble pas que ce soit le bas d'un modillon, mais plutôt les vestiges d'une moulure décorée, peut-être de perles et pirouettes.

Si un certain nombre de fragments permettent de restituer la structure de la corniche, il se trouve que deux autres donnent des renseignements sur l'architecture même du monument auquel ils appartiennent : il s'agit des blocs B 339 et B 340 qui ont tous deux une face de joint oblique par rapport à la mouluration. Il n'y a qu'une place possible pour ces éléments : le long du joint axial vertical au sommet d'un fronton dont la pente est de $35^{\circ}$. I e fragment B 339 se place au bas et à droite du bloc de gauche; B 340 au sommet et à gauche du bloc de droite ${ }^{30}$.

La localisation de la découverte de ces éléments est difficile à établir, mais semble correspondre à une mention dans le journal de fouille de 1906 relatant la mise au jour "des éléments de corniche de belle époque». Les fouilles avaient lieu alors dans l'espace compris entre le temple et la basilique. Cet indice, à lui seul, serait bien mince si, dans la fouille de 1974 , le docteur Sénéchal n'avait, à son tour, découvert un fragment semblable à cette série dans la couche superficielle du portique septentrional. Il faut donc

30 Pour faire la reconstitution graphique de cette corniche, a été rapproché et mis en position le plus grand nombre de fragments possible dans un espace réduit. En réalité aucun de ces fragments ne devait appartenir à un même bloc; ils servent ici pour reconstituer le schéma général de la corniche. Cependant, les rythmes des modillons et des feuilles du rais de cœur supérieur ne sont pas identiques : de ce fait, les fragments B 93 et B 63 ne peuvent en aucun cas être mis si près l'un de l'autre; cependant ils sont représentés ici en même temps, car sur B 93 le bandeau et le rais de cour se lisent bien alors que B 63 donne la liaison rais de cour/modillon - B 93 donne aussi la distance entre deux modillons comme le montre la fig. 14. Sur le dessin de façade. l'écartement a bien été respecté mais il n'a pas été possible de mettre le bloc à sa vraie place, pour concentrer le plus possible les informations : ce n'est pas gènant pour la restitution graphique qui est une démarche différente de l'anastylose, mais cela fait apparaitre une légère distorsion entre la photographie et le dessin. 


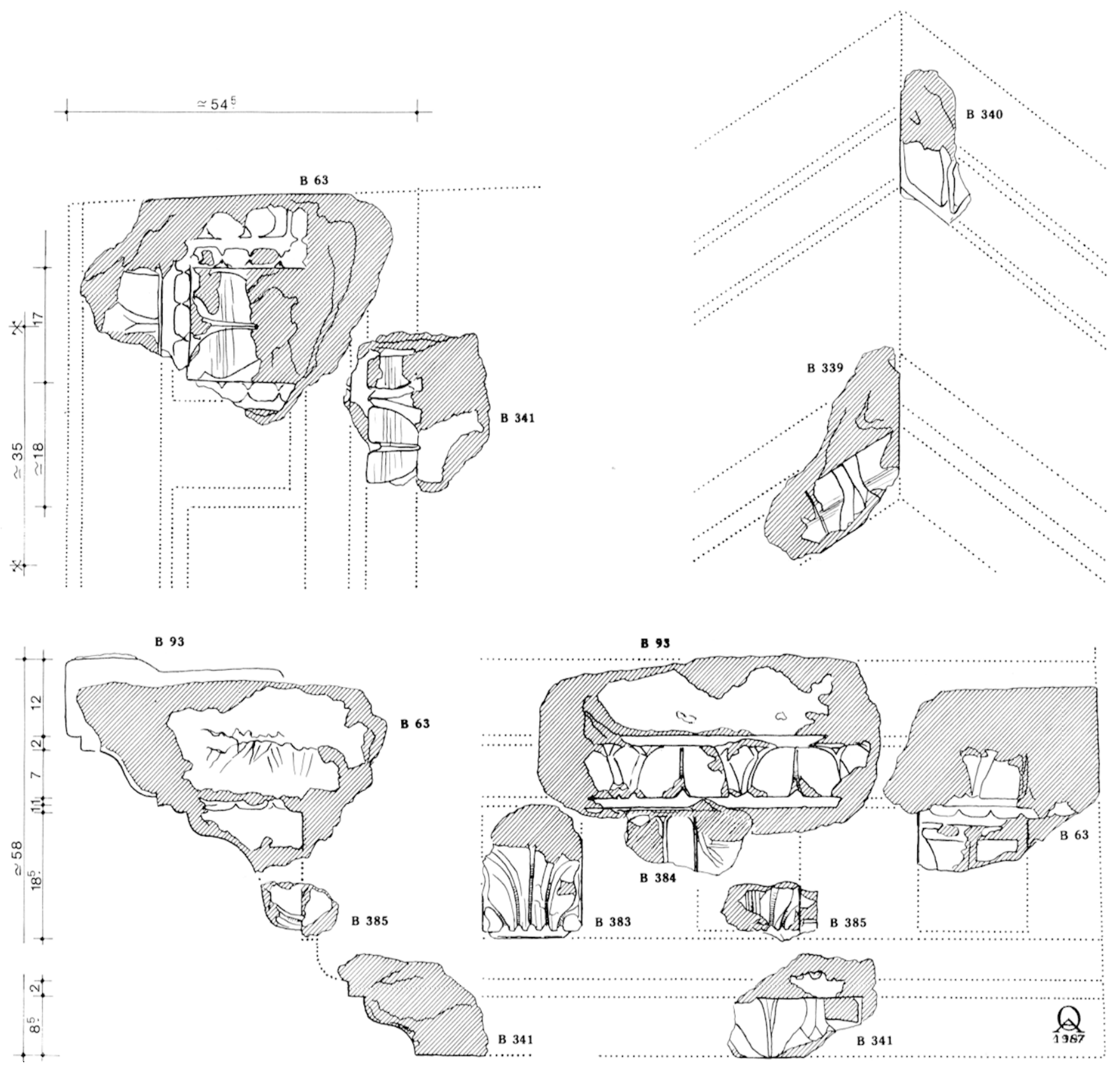

Fig. 12 - Éléments provenant du secteur monumental appartenant à une corniche modillonnaire à métopes ornées, mis en situation pour former une vue de face, une vue de dessous et une coupe; les petits fragments B 339 et B 340 peuvent ètre placés très précisément au sommet du fronton, cf. note 30. Échelle $1: 10$.

placer ces corniches sur une construction appartenant à l'ensemble monumental. La présence des éléments de corniche rampante et leurs dimensions incitent à rechercher un monument avec fronton d'une certaine ampleur. Un demi-tympan a été effectivement découvert dans cette zone, mais sa pente est différente et ne saurait convenir à ces éléments. Reste le temple, fouillé dans les années 1906-1907 : les vestiges sont très ruinés, réduits aux parties basses de la cella large de $7,50 \mathrm{~m}^{31}$. Selon

31 Journal manuscrit de Victor Prernet, conservé à la direction des fouilles d'Alésia (7 sept. 1906); - J. Le Gal.s, Un sanctuaire indigène au centre d'Alésia, in: llommage $\dot{a}$ Albert Grenier, (coll. Latomus, LVIII), Bruxelles, 1962, II, p. 981-994. toute vraisemblance, il pouvait se présenter sous la forme d'un temple prostyle avec fronton. Les proportions de ces éléments de corniche peuvent parfaitement convenir à un tel édifice qui devait être décoré de corniches horizontales et rampantes.

Pour le petit tympan dont il vient d'être fait mention il se trouve que deux blocs complets de corniche d'un autre type conservés au musée, ont la même pente et se superposent exactement à lui.

\section{DEUXIËME EXEMPLE}

\section{Description}

Le Bulletin de la Sociélé des Sciences de Semur, relatant la découverte du demi-tympan orné d'une figure féminine avec un amour, en 1906, signale la 

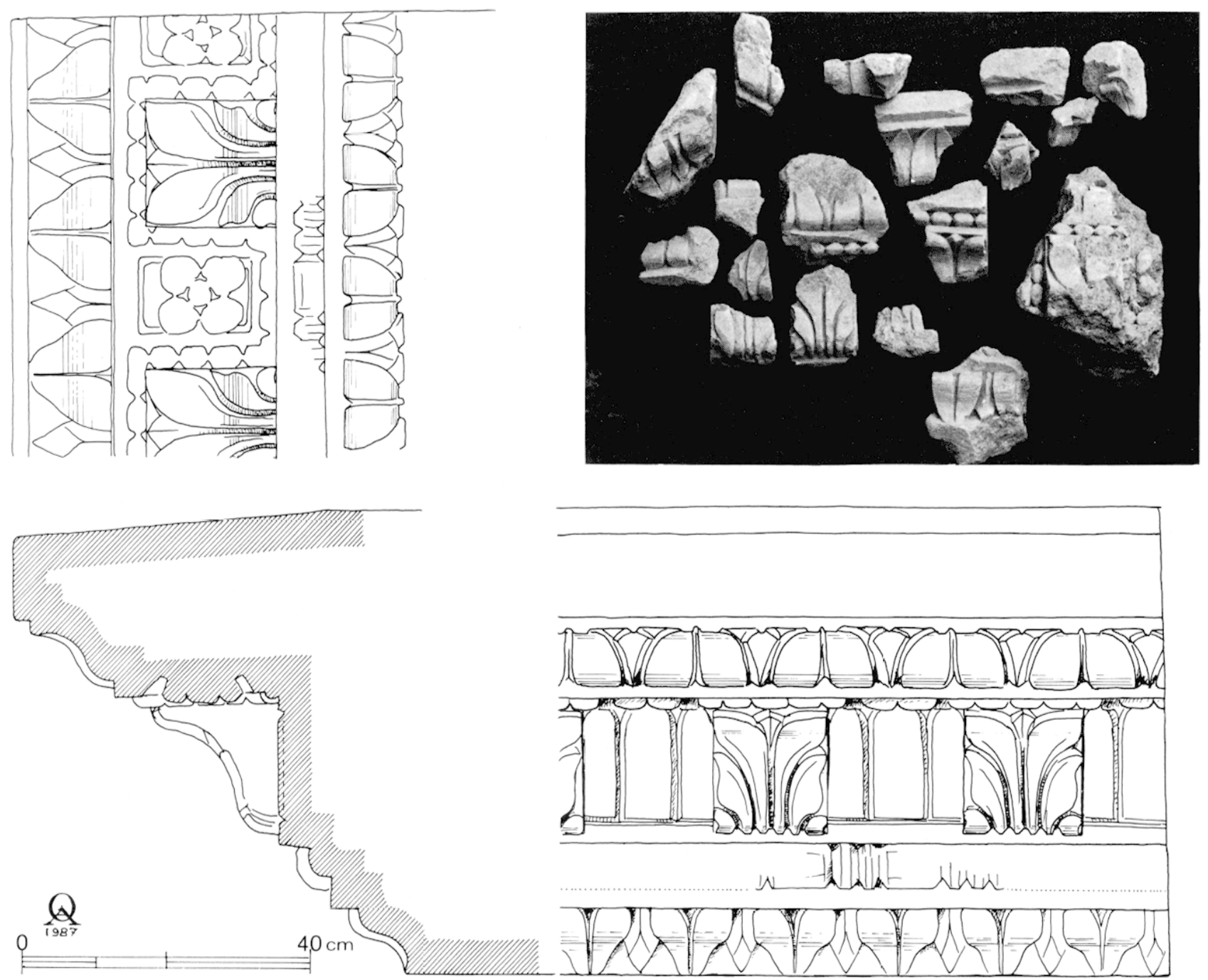

Fig. 13 - Restitution de la corniche à partir des fragments groupés sur la photographie et dessinés à la figure 12 . Échelle $1: 10$.

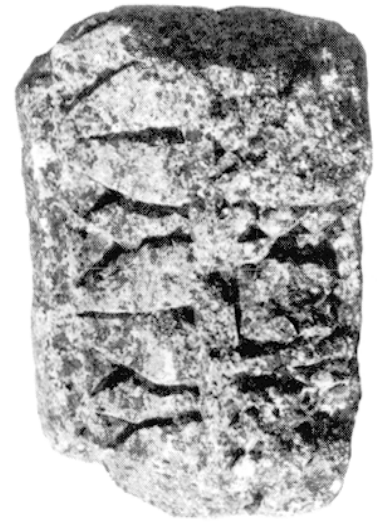

Fig. 14 - Elément le plus important B 93,

appartenant à la corniche restituée de la fig. 13 .

mise au jour au même endroit d'éléments architecturaux ornés de motifs en $\mathrm{S}$ et de corniches; une photographie les identifie : il s'agit de la corniche B 73 présentée au musée Alésia. Dans les réserves, un autre bloc, $B$ 333, aussi important mais plus mutilé, est de même facture (fig. 15 et 16).

Les corniches ont 35 à $36 \mathrm{~cm}$ de hauteur. Le bloc B 73 est intact, alors que le B 333 a beaucoup souffert : ce dernier est en plusieurs morceaux, son lit de pose presque entièrement arraché et ses deux faces de joints encore visibles par endroits. Sur le bloc intact B 73, il est facile de calculer le rapport $\mathrm{H} / \mathrm{L}$ légèrement inférieur à 1 , exactement 0,95 . La décoration se répartit de la façon suivante:

- le registre inférieur présente un talon orné d'un rais de cœur, un filet droit et un quart-de-rond décoré de perles et pirouettes; 


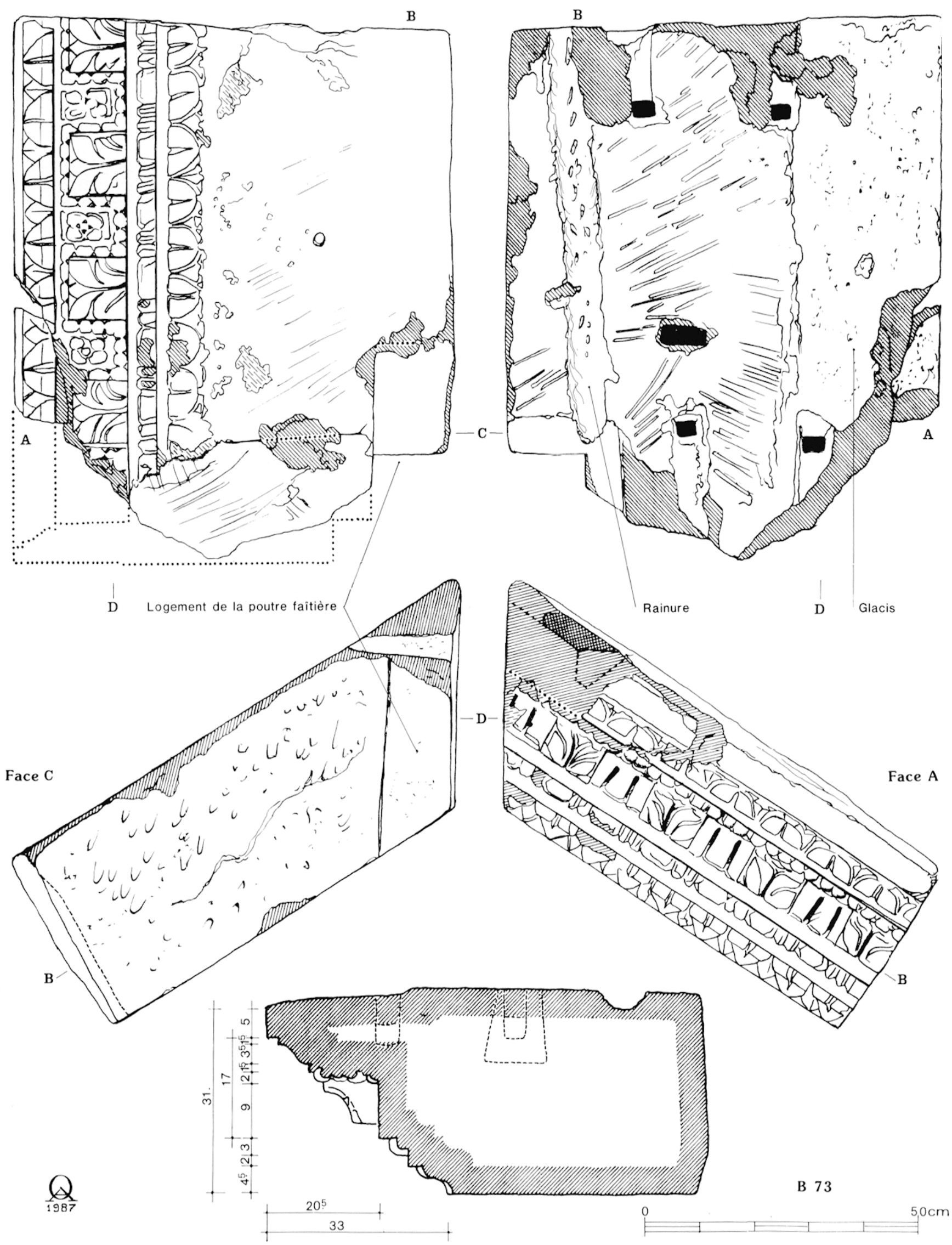

Fig. 15 - Corniche à métopes ornées B 73, provenant de la chapelle de "la déesse aux amours". Vues de dessus et de dessous; vue de face et vue arrière selon leur position dans le monument; coupe transversale. Echelle $1: 10$. 


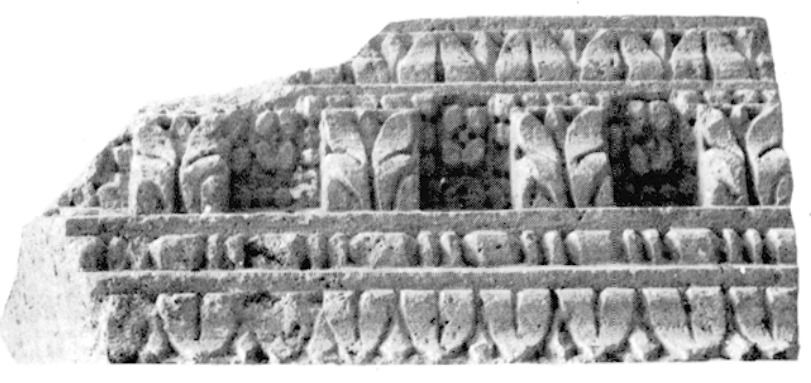

Fig. 16 - Corniche B 73 , provenant de la chapelle de "la déesse aux amours".

- au registre médian, des modillons en console larges de $11 \mathrm{~cm}$ et distants de 10 à $11 \mathrm{~cm}$ (entraxe : $21-22 \mathrm{~cm}$ ) sont revêtus d'une feuille souple à sept lobes avec un sillon médian légèrement courbe; les métopes sont ornées de deux rainures verticales soulignées par une rainure horizontale moins profonde, qui peut être interprétée comme un motif de godrons plats. La moulure de couronnement des modillons, profilée en quart-de-rond, est ornée de perles irrégulières; le champ rectangulaire du soffite est occupé par un fleuron allongé à quatre pétales et d'un bouton central, saillant de 1,5 à $2 \mathrm{~cm}$;

- au registre supérieur, une doucine ornée d'un rais de cœur entre deux filets est surmontée d'un bandeau lisse.

Un troisième bloc B 03 , cassé sur deux côtés et profond de $48 \mathrm{~cm}$, peut être rapproché de ceux-ci. Il a été trouvé beaucoup plus tard, en $1959^{32}$, lors d'enlèvement de déblais vers le théâtre. Ses moulures et ses dimensions sont en tout point semblables aux deux blocs précédents; seule la métope ornée de trois crosses est différente.

Le décor des métopes à Alésia se réduit à deux variantes, les godrons plats et les crosses. Si le motif des crosses est extrêmement fréquent à cette place, par exemple à Escolives-Sainte-Camille (Yonne), Autun (Saône-et-Loire) ou Langres (Haute-Marne), celui des godrons plats, en revanche, l'est beaucoup moins. La décoration des métopes est en général très variée et de nombreux motifs se côtoient sur un mème bloc ${ }^{33}$.

32 R. MARTin, Informations archéologiques, circonscription de Dijon, Gallia, XVIII, 1960, p. 331.

33 R. Kapps, Escolives Sainte-Camille gallo-romain, le site, le monument à arcades, $\mathrm{I}^{\text {er }}$ suppl. à la Revue archéologique de l'Est (RAE), Dijon, 1974; Mâlain-Mediolanum, Catalogue, Musée archéologique de Dijon, $1979, \mathrm{n}^{\circ *} 5$ et 6 , pl. 2 et 3 - Autun Augustodunum, Capitale des Eduens, Catalogue de l'exposition de 1985, Autun, 1987, no 106, p. 74-75, fig.; L. MaUrin, Saintes antique, op. cit., p. $415, \mathrm{n}^{0 \mathrm{~s}} 179,182,183$; - Ph. Brinfi, Le sanctuaire du Cigognier, Aventicum III, Cahiers d'Archéologie romande, 22, 1982.

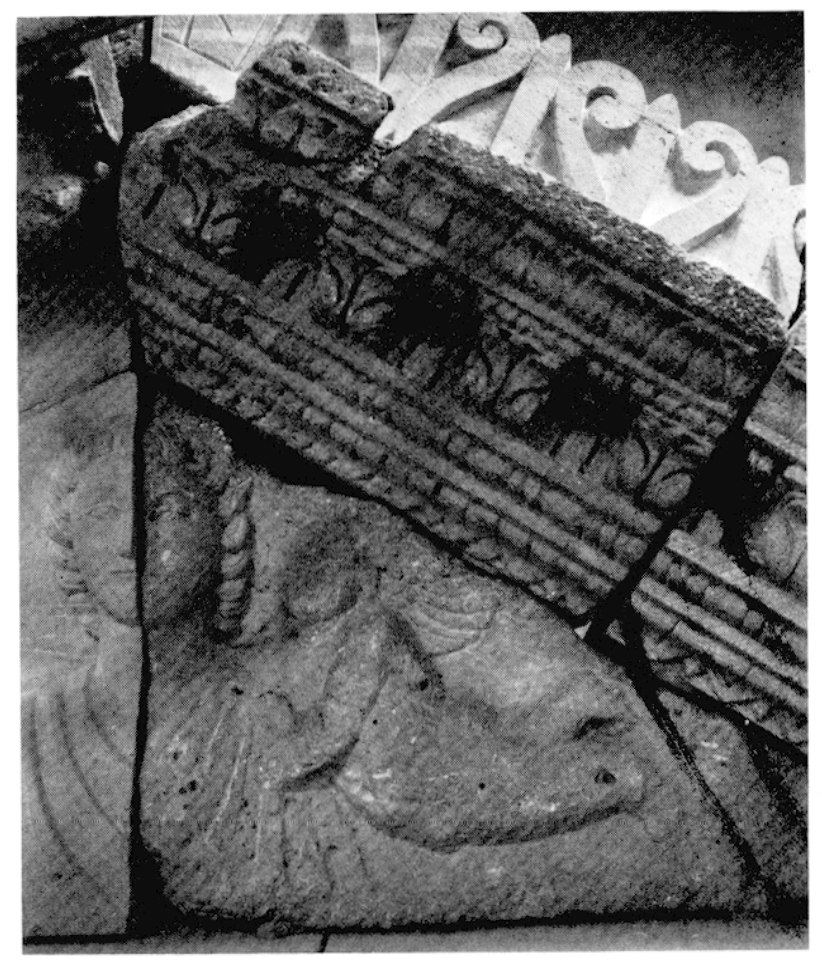

Fig. 17 - Superposition de la corniche B 73 et du demitympan B 01, de la chapelle de "la déesse aux amours".

Restitution du fronton de la chapelle de "la déesse aux amours "

Les faces de joints de B 73 et B 333 donnent des indications très précieuses sur la position de ces corniches: une des faces est perpendiculaire à la modénature et l'autre oblique : il ne peut s'agir que des blocs supérieurs de corniches rampantes, audessus d'un tympan. Le joint qui est oblique par rapport à la modénature, se trouve être vertical en réalité. La pente ainsi obtenue $(62,5 \%)$ est exactement la même que celle du demi-tympan trouvé dans les mêmes circonstances : il est donc permis d'envisager de superposer ces corniches au tympan ${ }^{34}$ (fig. 17).

De plus, sur leur face arrière les deux blocs comportent chacun une sorte de feuillure le long du joint vertical, large de 14 à $15 \mathrm{~cm}$ et profonde de $16,5 \mathrm{~cm}$ : ces feuillures se prolongent sur le sommet de la face postérieure du demi-tympan conservé et forment une alvéole où devait venir se loger la poutre faîtière. Cefte particularité rend tout à fait certaine l'appartenance de ces deux corniches et du demi-tympan au même édifice.

34 Cette pente de $62,5 \%$ est très proche de celle de $61,8 \%$ qui correspond à la diagonale du rectangle d'or. Le tympan restitué est inscrit dans deux rectangles dorés juxtaposés. 


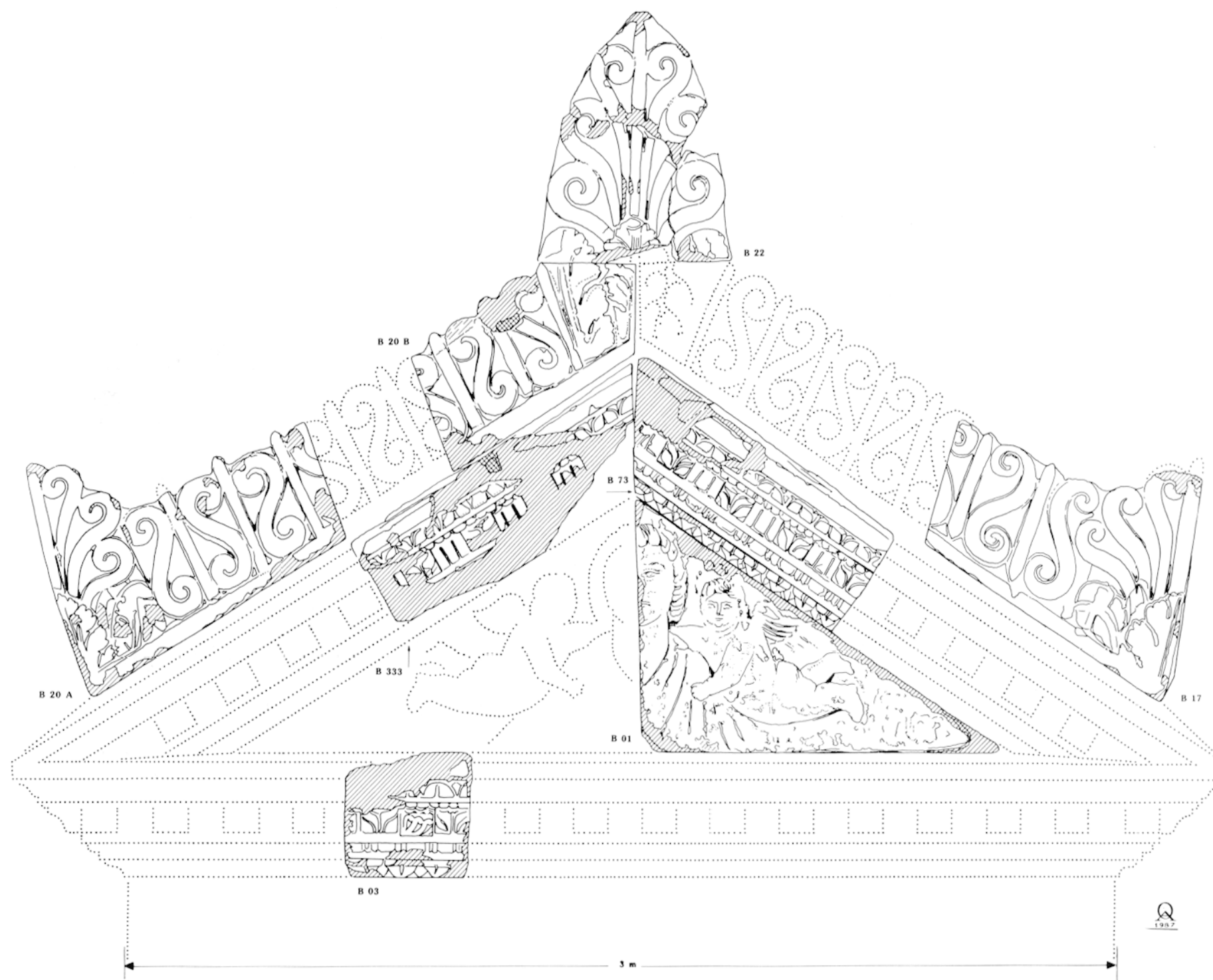

Fig. 18 - Chapelle de "la déesse aux amours", restitution du fronton. Échelle $1: 20$.

L'étude des corniches amène donc à reconsidérer la restitution de ce monument qui a été présentée par P. Varène en $1964^{35}$. Il s'agit d'un petit édifice à fronton, adossé à l'arrière de l'abside principale de la basilique civile : les fondations en grand appareil en sont encore bien visibles (largeur : $3,11 \mathrm{~m}$; profondeur : 2,57 à $2,81 \mathrm{~m})$.

L'insertion des corniches a pour effet de changer les proportions de la restitution du fronton en lui donnant plus d'ampleur. La longueur de l'entablement mesuré en bas de la corniche est de $2,96 \mathrm{~m}$ à $3 \mathrm{~m}$, ce qui correspond à la largeur utile des fondations conservées $(3,11 \mathrm{~m})^{36}$. De plus, elle donne

35 P. Varíne, Petit édifice d'Alésia à décor en spirales, Gallia, XXII, 1964, p. 63-85, spécialement p. $75 s q$.

36 Dans la précédente restitution, les épaufrures des blocs supérieurs des fondations ont été considérées comme des chanfreins : au réexamen, il s'agit de biais très irréguliers résultant du passage répété des engins agricoles. L'incertitude sur la longueur exacte de la frise (ou de la base de la corniche) est lièe à l'absence de certains blocs importants comme le demi-tympan et à la taille assez approximative des blocs de un nouvel aspect plus classique à cette chapelle où le tympan sculpté se trouve enchâssé dans un cadre triangulaire de corniche selon une formule très répandue (fig. 18 et 19 ). Il ne s'agit pas ici de redécrire l'ensemble des blocs qui ont été exposés dans la précédente étude de $P$. Varène - le tympan, les blocs décorés de $\mathbf{S}$ - mais simplement de réexaminer certains points à la lumière des éléments nouveaux apportés par ces corniches : l'alvéole de la poutre faitière à l'arrière du fronton, la liaison des corniches entre elles et la place des acrotères et couronnements qui leur sont superposés (fig. 20, 21, 22).

- Le logement de la poutre faîtière : le bloc de tympan porte à l'arrière une encoche pour appuyer la poutre faîtière du toit qui couvrait ce petit édifice à fronton. Cette encoche se prolonge verticalement

calcaire. Quoi qu il en soit, cette cote est si proche de dix pieds romains qu'il est tentant de la considérer comme l'une des données du programme imposé au constructeur. 


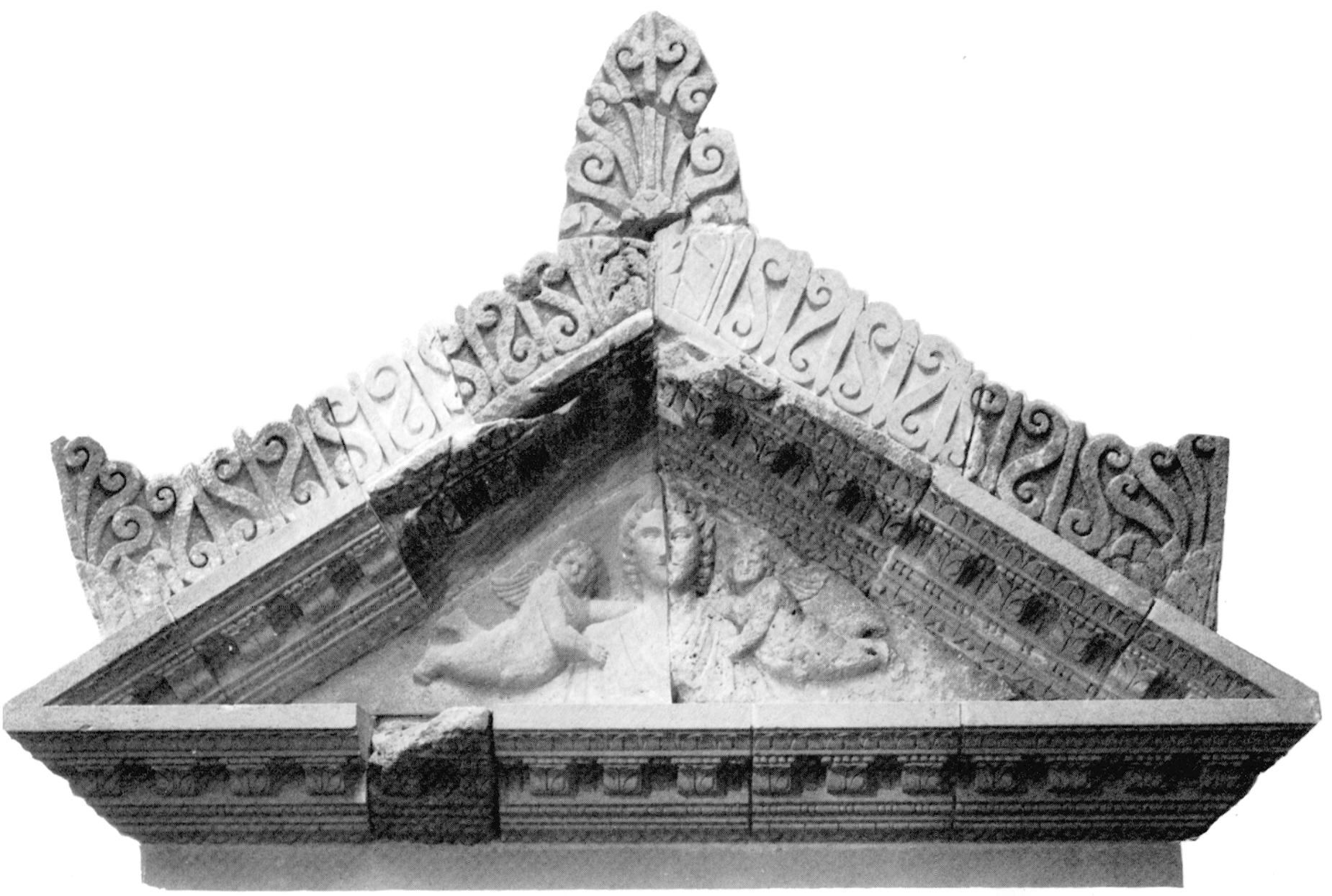

Fig. 19 - Musée Alésia : fronton de la chapelle de «la déesse aux amours» reconstitué en mars 1987.

dans les deux blocs de corniches et crée ainsi un logement de $16,5 \mathrm{~cm}$ de profondeur, large de $30 \mathrm{~cm}$ et haut de $35 \mathrm{~cm}$, permettant de placer une poutre ayant une section de $30 \mathrm{~cm}$ de côté environ. Cette poutre devait soutenir une toiture et une faitière ornée, entièrement en pierre. La feuillure à l'arrière des corniches ne se prolonge pas jusqu'au sommet : il semble que la poutre était couronnée par un petit bloc de pierre taillée en bâtière qui permettait de rétablir la continuité de la pente des corniches (fig. 20).

- La liaison des corniches entre elles était assurée par des agrafes en $\boldsymbol{\Pi}$ dont les traces sont très nettes : il y avait deux agrafes à chaque joint pour assembler les blocs entre eux. Pour lier les deux blocs au sommet, le constructeur a utilisé des agrafes coudées pour éviter d'entailler la pierre trop profondément: la forme des trous plus évasée qu'à l'ordinaire, visible sur le bloc B 73, permet de déduire que les agrafes étaient introduites verticalement, le plomb comblant le vide et assurant la parfaite cohésion de l'ensemble (fig. 20). Cette tech- nique de liaison par agrafe n'était pas réservée aux corniches puisqu'elle s'observe sur les blocs de fondation encore en place.

Les quatre blocs d'acrotère exhumés dans les fouilles peuvent maintenant être replacés sur ces corniches grâce à l'examen des traces visibles sur le lit d'attente en tenant compte de la largeur des lits de pose des acrotères. Trois sortes de traces s'observent sur les blocs B 73 et B 333 (fig. 21) : en avant le long de la façade, un glacis en légère pente, large de $25 \mathrm{~cm}$, visiblement érodé par les agents atmosphériques; au milieu, une large plage d'une quarantaine de centimètres ayant conservé, très visibles, des traces d'outil; à l'arrière, enfin, une rigole large de 6 à $8 \mathrm{~cm}$ et profonde de 3 à $4 \mathrm{~cm}$.

Il n'y a qu'une place possible pour ces blocs de couronnement, c'est la plage médiane : en effet, ils ne peuvent se placer sur le bord des corniches à cause de la présence du glacis, en pente, trop étroit et érodé de surcroît. Cette position médiane est aussi la meilleure pour la stabilité de l'ensemble puisque le parement de ces blocs d'acrotère est pratiquement à 

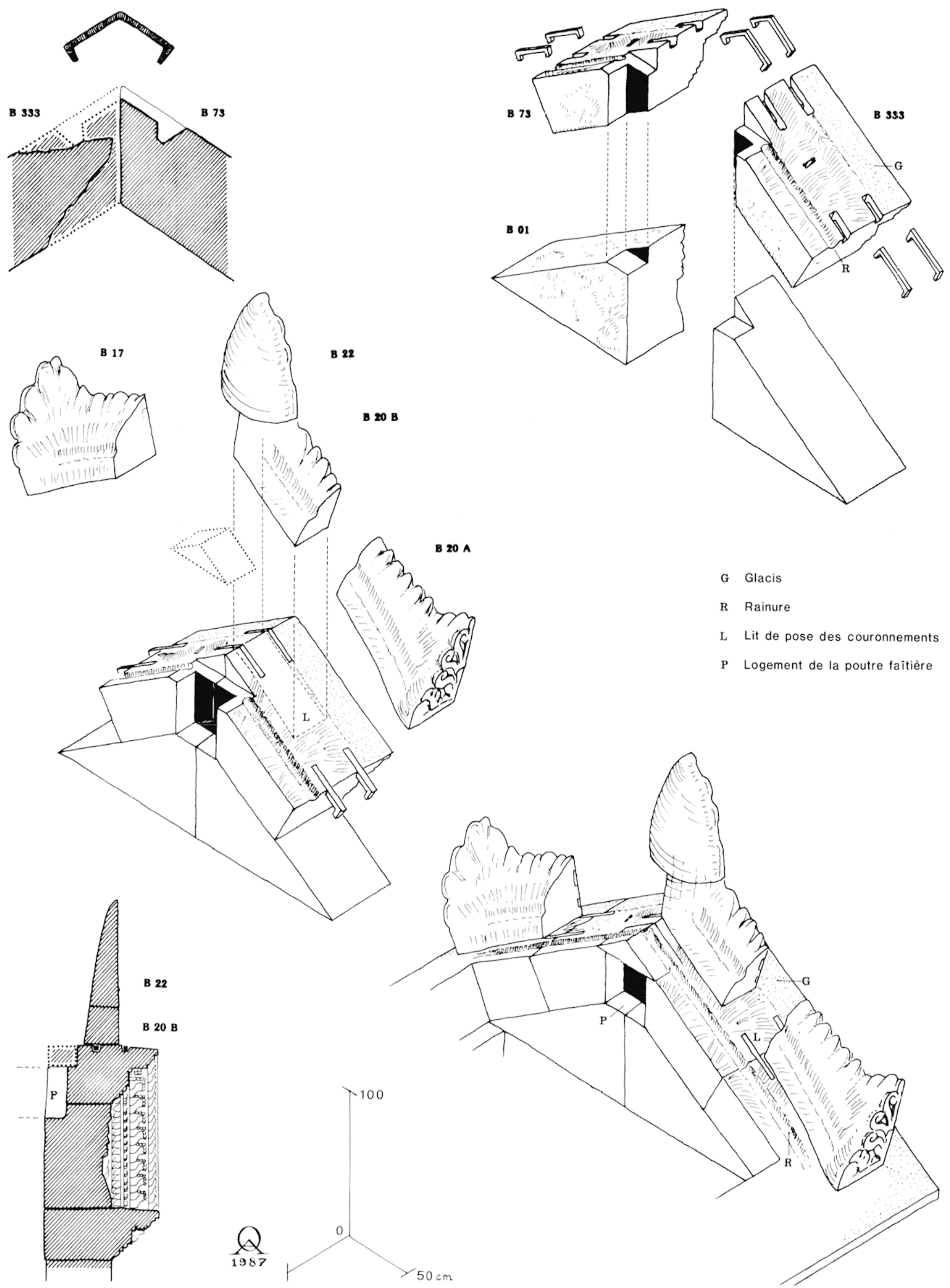

Fig. 20 - Fronton de la chapelle de "la déesse aux amours".

Trois schémas axonométriques montrant la superposition des blocs, vue de l'arrière; échelle $1: 40$. Coupe transversale du fronton restitué; échelle 1:40. Détail de l'agrafe liant les deux corniches rampantes au sommet du monument; èchelle $1: 20$. 


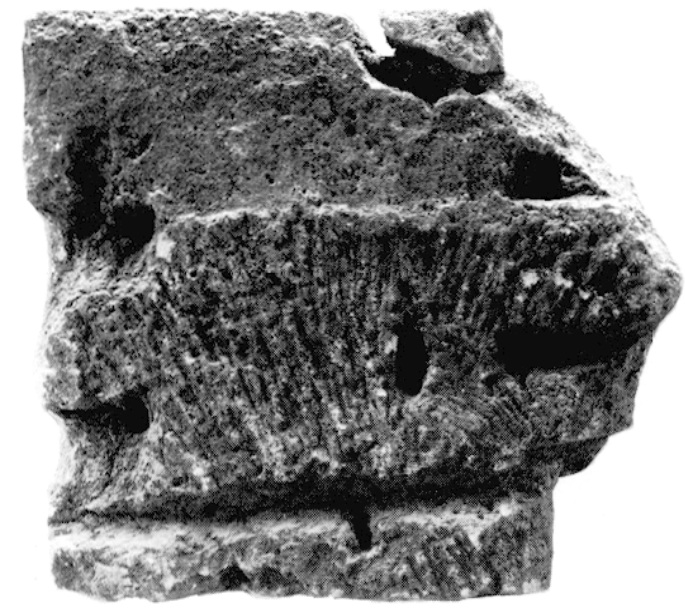

Fig. 21 - Lit d'attente de la corniche B 73. Le glacis exposé aux intempéries est en haut; la feuillure pour le logement de la poutre faîtière est en bas à droite.

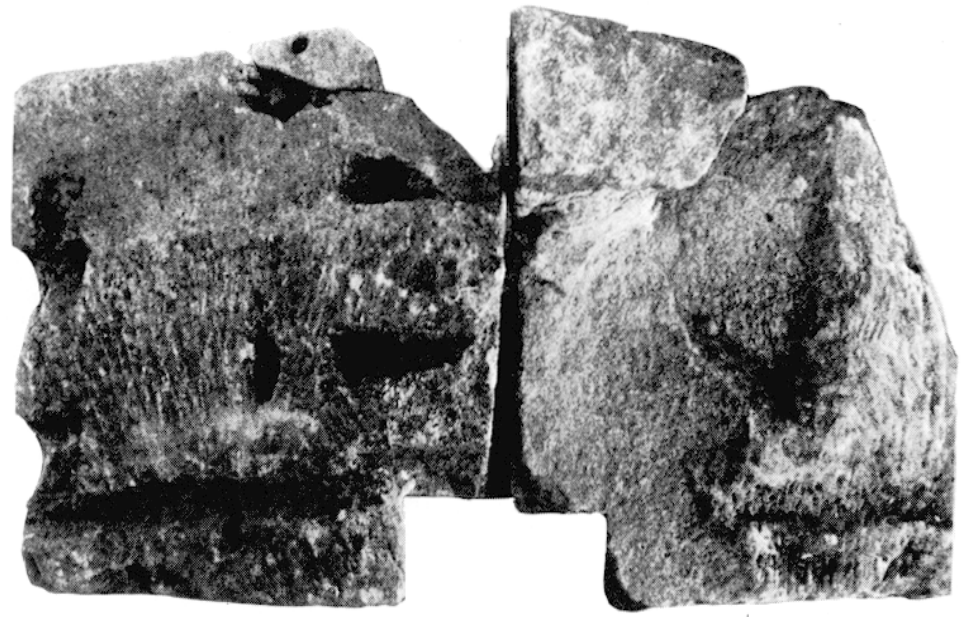

Fig. 22 - Les deux corniches B 73 et B 333 : vue verticale au moment du montage. Lorsque ces deux blocs sont à leur place, les deux feuillures forment une alvéole importante très bien découpée. l'aplomb du tympan (fig. 20).

Cette restitution lie, d'une façon sûre, des corniches et des blocs de couronnement de forme originale. D'autres blocs semblables, mais de proportion différente, ont été trouvés sur le plateau d'Alésia, et il est utile de les réexaminer à la lumière de cette restitution.

\section{LES COURONNEMENTS}

Alésia a le privilège de conserver des blocs de couronnement qui ont attiré l'attention des chercheurs depuis longtemps ${ }^{37}$. Les exemples conservés sont de tailles différentes et appartiennent au moins à trois ensembles. Un bloc de rive isolé, de grande taille $B 14$ avec des $S$ de $55 \mathrm{~cm}$, un acrotère axial avec l'amorce des rives de module très réduit, $\mathrm{B} 51$, avec des $S$ hauts de $13 \mathrm{~cm}$, décorant probablement un petit édicule, et un ensemble plus complet de quatre blocs bien conservés, trouvés à proximité des fondations de la chapelle de "la déesse aux amours". Ces couronnements présentent l'originalité de lier l'acrotère axial aux acrotères d'angle par une "rive»" continue décorée de motifs en $\mathrm{S}$ alternativement

37 J. Toutain, Note sur les éléments de décoration architecturale découverts à Alésia, Bulletin archéologique du Comilé des Travaux historiques et scientifiques, 1913, p. 408-422, pl. XLIII-XLVI ; - P. VARÈnE, Autres blocs d'Alésia à décor en spirales, RAE, XXIII, 1972, p. 101-118; - Ch. PICARd, Acrotères, antéfixes, chapiteaux héllénistiques à décor mêlé, humain et végétal : de Samothrace à la vallèe du Pô et à Glanum, Revue archéologique, 1963, 2, p. 113-187. droits et inversés, séparés par des hastes ${ }^{38}$. L'intérêt s'est plus porté sur l'origine et la signification du décor que sur la forme architecturale de ces éléments. Les acrotères ne sont plus des éléments isolés posés sur des socles, eux-mêmes intégrés aux corniches et placés aux angles et au faite d'un fronton, mais un élément continu triangulaire intégrant sans interruption les décors feuillus des acrotères à palmettes avec les $\mathrm{S}$ des rives. Cela devient une pièce d'architecture originale qui coiffe la corniche.

Les quatre éléments conservés de cette chapelle sont particulièrement significatifs à cet égard, puisque le hasard a voulu que subsistent les deux acrotères latéraux avec l'amorce des rives, l'acrotère central en deux parties : la moitié gauche du décor feuillu avec l'extrémité de la rive et la palmette proprement dite. Les éléments manquants se restituent facilement par symétrie, mais se pose la question de la longueur de l'ensemble. En effet, dès leur découverte, les deux blocs appartenant au côté gauche du fronton, $\mathrm{B} 20 \mathrm{~A}$ et $\mathrm{B} 20 \mathrm{~B}$, ont été associés car le décor paraissait continu ${ }^{39}$. Cette impression a

38 Le mot "rive", désignant la limite latérale d'un toit, semble parfaitement convenir pour ces membres d'architecture qui peuvent être monolithiques ou formés d'une suite de «blocs de rive" ou encore des éléments de placage.

39 S'il est vrai que, de prime abord, le décor de ces deux blocs semble pouvoir se raccorder, un examen attentif montre que la distance des deux hastes de part et d'autre du joint est un peu supérieure à celle de leurs homologues immédiatement voisines, que le raccord des deux parties du S coupé par le joint présente un décalage de plus d'un centimètre lorsque les deux blocs sont posés sur le même plan, enfin que l'épaisseur des blocs est différente, créant au revers un décrochement de plusieurs centimètres à leur jonction. 


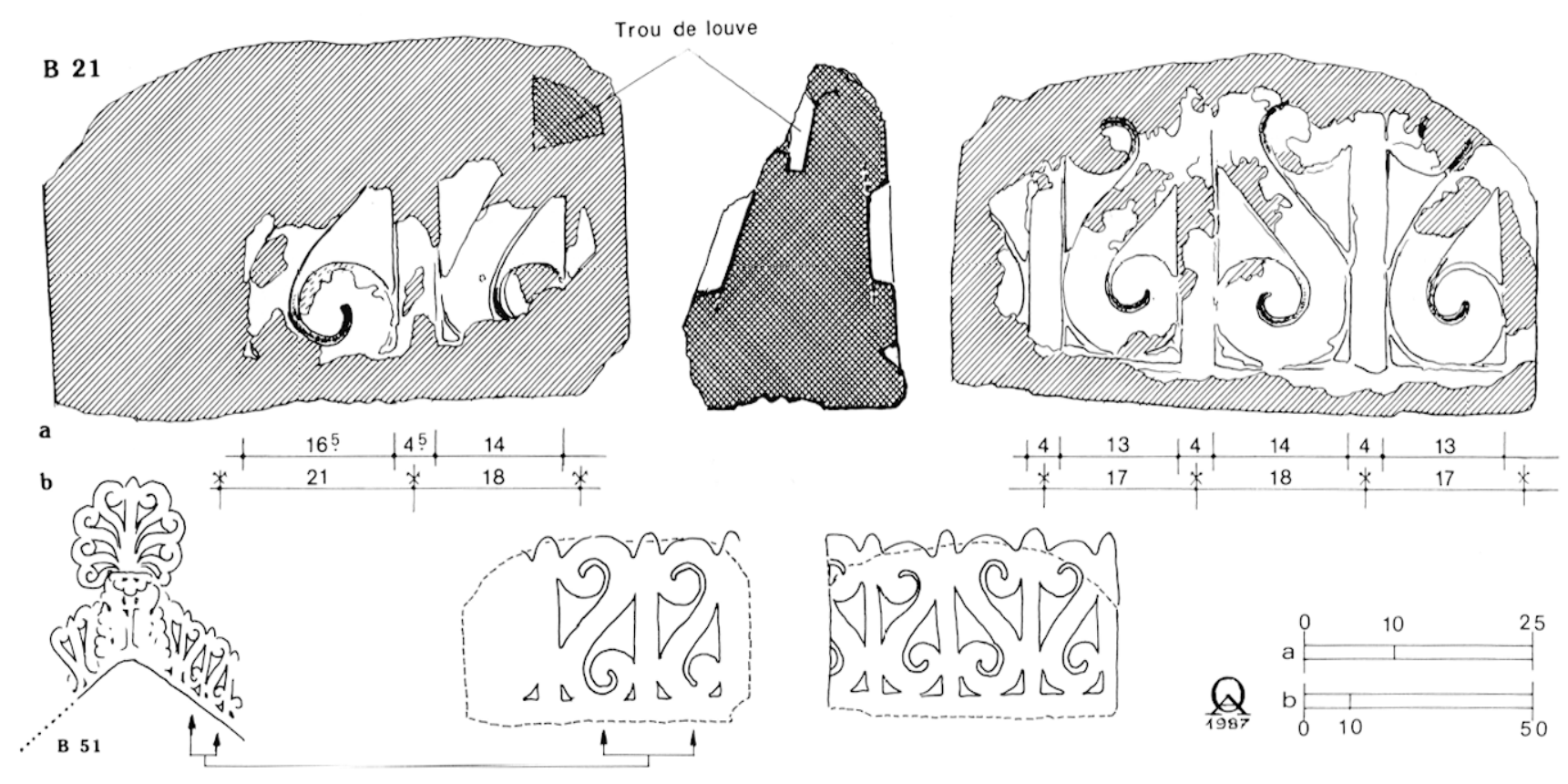

Fig. 23 - a, Faitière B 21 : les deux faces et la coupe transversale, échelle $1: 10$.

b, Acrotère central avec amorce des rives $\mathrm{B} 51$; mise en parallèle de l'anomalie du décor consistant en deux $\mathrm{S}$ inversés juxtaposés observée sur les deux blocs, échelle $1: 20$.

été déterminante pour la précédente restitution, mais l'introduction des corniches à leur vraie place, rend impossible le maintien de cette hypothèse.

Le problème de la position des acrotères d'angle et de la longueur des rives reste à résoudre, car malheureusement, les deux blocs des extrémités de la corniche qui auraient pu donner des indications sur la place et la fixation des acrotères, n'ont pas été conservés.

L'examen du lit d'attente des corniches a montré qu'un glacis de $25 \mathrm{~cm}$ existait le long de leur bord: les blocs de rive ne peuvent pas lui ètre superposés et doivent donc se situer en retrait sur la partie plate médiane. D'autre part, ces corniches n'ont pas de trous de scellement pour fixer les blocs de rive et les empêcher de glisser; ceux-ci ont euxmêmes des lits de pose parfaitement lisses et ne possèdent aucune trace d'agrafe de liaison entre eux. Or, même si la pente n'est pas suffisamment forte pour que les blocs glissent sur la corniche, il est très vraisemblable que les constructeurs aient prévu un ressaut de calage sur le lit d'attente des corniches d'angle pour s'opposer à tout mouvement. Le manque de liens entre ces éléments supérieurs contraste avec le soin apporté, dans ce domaine, dans les autres parties conservées de la chapelle: fondations et corniche. Lors de la construction même, l'absence d'une butée en partie basse, aurait rendu périlleux l'assemblage des blocs sur la pente du fronton. Dans la restitution réalisée au musée
Alésia, le calage a été réduit au minimum mais il est très possible d'envisager un ressaut plus conséquent. En l'absence d'informations sur les angles, il est logique de réserver un retrait analogue entre le retour de l'acrotère d'angle et le bord de la corniche des longs pans : en admettant ce point de vue, la longueur de la rive doit être de $1,90 \mathrm{~m}$ et il faut introduire entre les deux blocs existants un petit bloc d'environ $36 \mathrm{~cm}$, ce qui correspond à deux motifs consécutifs, deux $\mathrm{S}$ et deux hastes; de ce fait, l'alternance des motifs est parfaitement respectée.

Pour le côté droit, l'acrotère d'angle est flanqué d'une portion de rive où les entraxes des motifs sont légèrement différents de leurs homologues de gauche : de ce fait, sur la longueur du rampant, le nombre de $\mathrm{S}$ est de sept à droite et de huit à gauche; $\mathrm{P}$. Varène a cru devoir écarter ce bloc de sa restitution, pour cause d'asymétrie. Cependant, les deux acrotères ont exactement la même allure d'ensemble, les différences ne sont que des détails. Les motifs ont, de toute évidence, été taillés une fois les blocs posés ${ }^{40}$ : il suffit d'une différence d'entraxe de $3 \mathrm{~cm}$ pour avoir un décalage. Cette irrégularité se constate sur

40 Les blocs ont certainement été ravalés sur place : c'est manifeste pour le tympan où le joint qui sépare les deux blocs passe dans l'axe du nez de la déesse. De plus sur le bloc de rive $B 20 \mathrm{~B}$, un trou de louve est visible dans le décor de façade, alors que primitivement il devait se situer au centre de gravité du bloc : cette anomalie ne peut s'expliquer que par un très important ravalement du bloc après la pose. 

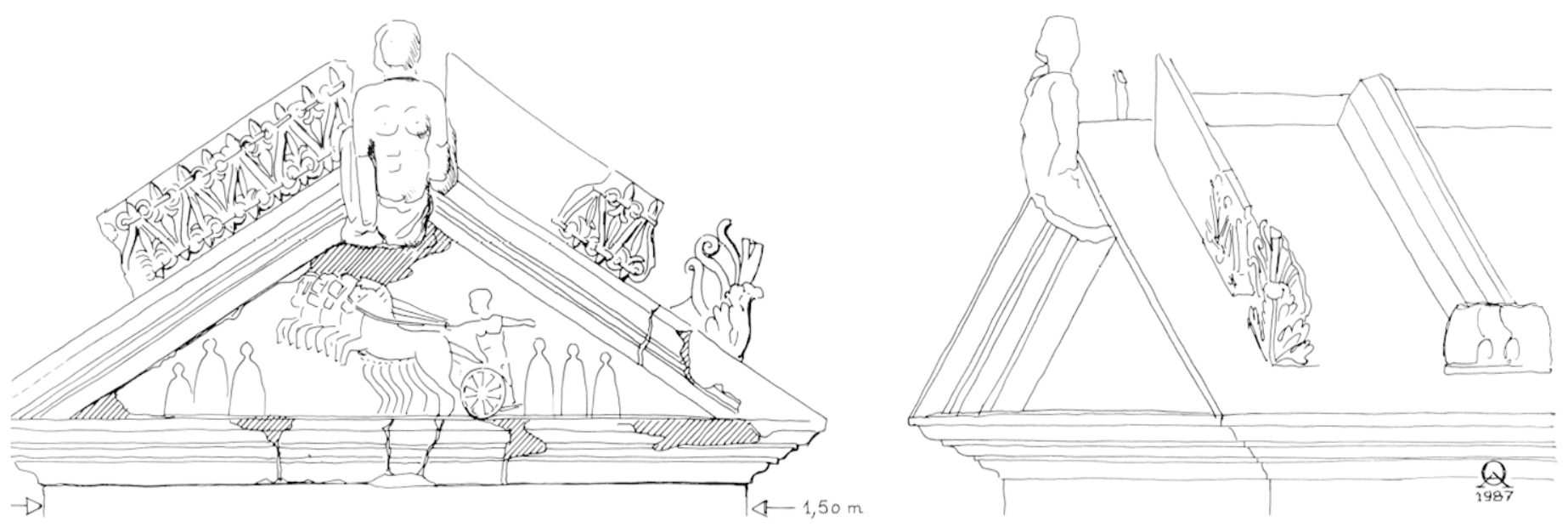

Fig. 24 - Monument funéraire des Volumnii, musée archéologique de Padoue : élévations frontale et sur l'angle. (Ces croquis ont été faits d'après les photographies du catalogue).

d'autres éléments conservés à Alésia : par exemple la faîtière B 21 appartenant à cette même chapelle, possède sur une de ses faces des entraxes de 17 et $18 \mathrm{~cm}$, et sur l'autre de 18 et $21 \mathrm{~cm}$ (fig. 23). La réduction du nombre des motifs à un chiffre impair suggère deux solutions: ou bien l'alternance est maintenue régulièrement jusqu'au sommet et une petite asymétrie apparaîtra au voisinage de l'acrotère central qui sera flanqué de chaque côté par des $\mathrm{S}$ de même sens : c'est la solution qui a été adoptée pour la présentation dans le musée, et il faut bien reconnaître qu'aucun visiteur, même prévenu, ne le remarque; ou bien, inversement, c'est la symétrie au sommet qui prédomine, et il faudra, alors, que, dans la partie manquante de la rive, deux $\mathrm{S}$ droits ou inversés se suivent. Cette formule qui peut, a priori, paraître bizarre, est parfaitement possible ; la faîtière même de cette chapelle (B 21) présente cette anomalie sur l'une de ses deux faces (fig. 23 a). Au musée Alésia, l'acrotère central de beaucoup plus petite dimension, B 51, flanqué de l'amorce des deux rives ornées de $\mathrm{S}$, possède bien deux $\mathrm{S}$ consécutifs de même sens sur sa rive droite (fig. $23 \mathrm{~b}$ ).

Il ne faut donc pas se fonder sur l'alternance des motifs pour calculer la longueur de la rive : il faut plutôt faire des comparaisons avec des édifices existants. Cette rive ne peut être considérée comme une cimaise puisqu'elle ne se place pas sur le bord de la corniche : c'est une pièce d'architecture liée aux acrotères qui, normalement, sont toujours en retrait.

Une comparaison italienne peut éclairer cette disposition. Une tombe conservée au musée de Padoue, le monument funéraire des Volumnii présente un entablement à fronton sculpté surmonté d'acrotères d'angle et de rives ornés de motifs en $S$ très proches du décor alisien ${ }^{41}$. La toiture de ce petit édicule funéraire haut de $3,90 \mathrm{~m}$, large de $1,50 \mathrm{~m}$ et profond de $1,05 \mathrm{~m}$, tout en marbre, copie une toiture en terre cuite avec imbrices et antéfixes. L'acrotère d'angle est placé en retrait à la même distance des bords des façades principales et latérales (fig. 24).

Cette comparaison suggère aussi une autre hypothèse : un motif en $\mathrm{S}$ ne serait-il pas l'interprétation en pierre de tuiles de rive en terre cuite? Les toitures de pierres étaient très souvent employées dans la Gaule de l'Est avec un agencement particulier en opus pavonaceum ${ }^{42}$. Or, c'est ce type de couverture qui devait recouvrir celle chapelle car dans les morceaux d'architecture retrouvés, figure une faîtière en pierre, B 21, bien caractéristique de ces toitures. La bordure latérale de ces toits demandait à être confortée et protégée : ces corniches à modillons sans cimaises fonctionnelles ne permettent pas le calage latéral de ces couvertures rendues particulièrement épaisses par le triple recouvrement des dalles. C'est peut-être la raison de l'introduction de ces rives continues qui, joignant entre eux les acrotères, présentent un front décoré s'opposant aux infiltrations d'eau et aux effets du vent. Sur les revers des rives de cette chapelle d'Alésia, se trouve une saignée qui pouvait servir d'ancrage à un cordon

41 Fr. Ghedini, Sculture greche et romane del museo civico di Padova, Rome, 1980, p. 104-113, no 42, edicola funeraria dei Volumnii.

42 A. Olivier, Mâlain Mediolanum, A, La couverture en dalles sciées du fanum des Froidefonds, RAE, XXVI, 1975, p. 235-246; - ID., Les dalles de toiture en pierre sciée à Glanum, "opus pavonaceum "et R. Hanoune, Pline, H.N., $\mathrm{XXXVI}, 159$ et "l'opus pavonaceum», RAN, XV, 1982, p. $69-$ 101 . 
de scellement au mortier: ce dernier était aussi maintenu dans la rigole observée sur le lit d'attente des corniches; il devait lier les dalles de pierre avec les rives et les corniches et assurer l'étanchéité dans cette partie vulnérable de la toiture ${ }^{43}$.

43 A Glanum où les toitures en pierre sont bien attestées, on trouve aussi des blocs ornés de motifs en $S$ : II. Rolland cite des faîtières mais il existe peut-être aussi des rives. H. Rolland, Fouilles de Glanum 1947-1956, $11^{\circ}$ suppl. à Gallia, 1958, p. 25-26 et pl. 6.

$44 \mathrm{P}$. Varène, dans son article cité, plus haut $(R A E$, XXIIII, 1972, p. 104) avait déjà évoqué la possibilité d'attribuer ce bloc au temple.

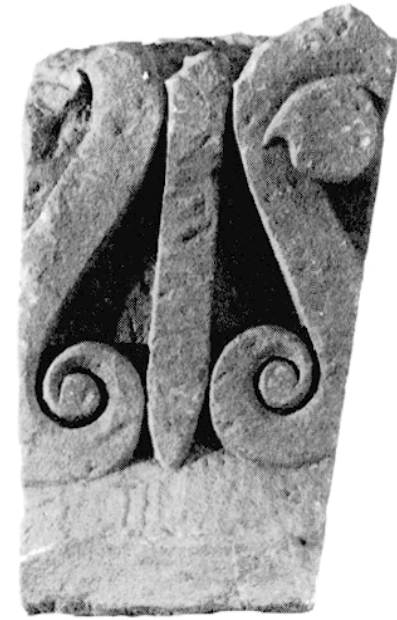

Fig. $25-$

Bloc de rive $B 14$.
Le grand bloc B 14, aussi décoré de S. que possède le musée Alésia, pose un problème intéressant; il ne peut bien sûr être intégré à l'ensemble de la chapelle de "la déesse aux amours". Haut de $68 \mathrm{~cm}$, profond de $51 \mathrm{~cm}$ et large de $35 \mathrm{~cm}$, ce bloc complet et presque intact a une large base avec plinthe et un grand décor formé de deux $\mathrm{S}$ opposés séparès par une haste (fig. 25). Les faces de joint avec cadre d'anathyrose sont obliques par rapport au décor : il s'agit assurément d'un élément de rive, mais ses proportions imposantes supposent un fronton important. Parmi les corniches étudiées précédemment, seule celle attribuée au temple dit de "Taranis" a des dimensions suffisantes pour le supporter ${ }^{44}$. La superposition de ces deux éléments fait apparaitre des rapports de proportion, rive sur corniche, identiques entre le temple et la chapelle (fig. 26). Cette proposition d'assemblage amène à supposer que, dans l'ensemble monumental d'Alésia, deux frontons de même conception se faisaient face, celui du temple et celui de la chapelle de "la déesse aux amours", ce qui ferait penser à une volonté délibérée de composition architecturale. Cependant, il est peu probable que ce soit le résultat d'un projet unitaire : il semble que la chapelle ait été construite postérieurement pour faire face au temple et qu'elle se présentait comme un rappel de celui-ci.

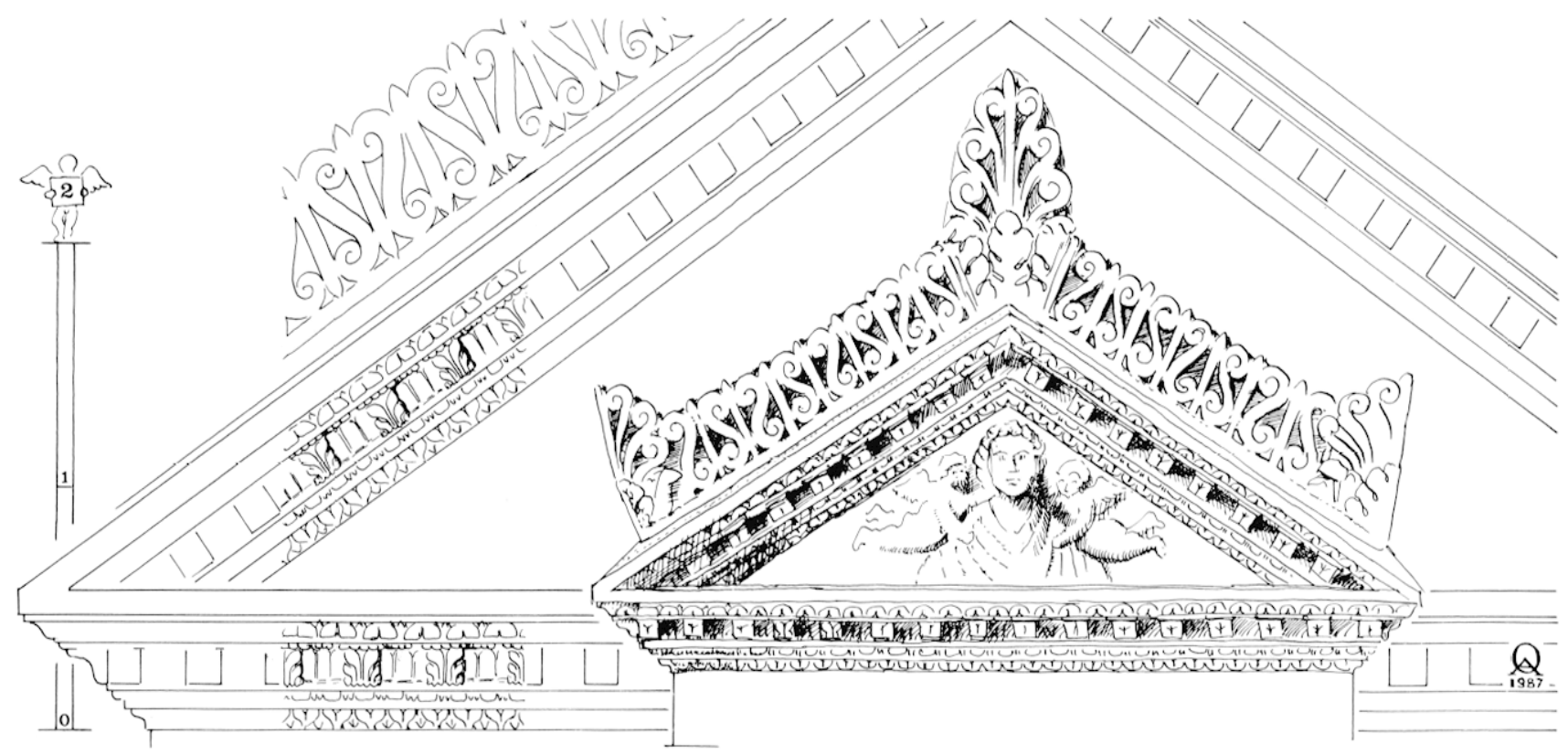

Fig. 26 - Juxtaposition à la mème échelle des frontons de la chapelle de "la déesse aux amours" et du temple selon l'hypothèse présentée ici. Échelle 1:40. 
La présence de rives décorées de motifs en $\mathbf{S}$ sur des monuments de grandes dimensions, si surprenante qu'elle puisse apparaître, est aussi attestée à Langres (Haute-Marne). Son musée archéologique conserve lui aussi des éléments de très grandes dimensions, spécialement un acrotère avec amorce de rive et une autre rive de $76 \mathrm{~cm}$ de hauteur, qui ne peuvent appartenir qu'à des monuments conséquents ${ }^{45}$ (fig. 27 et 28). Dans la région, si les exemples de Langres et d'Alésia sont les plus grands recensés actuellement, les éléments de dimensions moyennes sont plus fréquents. Des découvertes récentes à Langres (fig. 29) et à Nod-sur-Seine en forêt de Châtillon (Côte-d'Or) ${ }^{46}$ (fig. 30) ont apporté des

45 La présentation de ces blocs au musée de Langres ne facilite pas leur analyse : en effet, ces éléments sont ennoyés dans un massif de plâtre qui ne laisse voir que les parements. Ils portent le même numéro et ont été trouvés à Langres mème. Catalogue du Musée de Langres, Langres, 1931, no 377.

46 A Langres, lors des travaux de voirie en 1969, ont été mis au jour un important bloc de corniche et plusieurs fragments inédits de plaques de $30 \mathrm{~cm}$ de hauteur, épaisses de $10 \mathrm{~cm}$, ornées sur chaque face de $S$ alternativement droits et inversés, séparés par des hastes avec des attaches. A Nod, il s'agit de nombreux fragments de rives sous forme de plaques d'une douzaine de centimètres d'épaisseur et hautes de $30 \mathrm{~cm}$, mis au jour dans la fouille de deux chapelles à enclos. Je remercie vivement Monsieur $R$. Paris d'avoir autorisé la publication d'une photographie de l'un de ces éléments encore inédits. Cf. H. Gaillit.ard de Semainvilu.e, Informations archéologiques, Bourgogne, Gallia, 43, 1985, p. 259. éléments nouveaux aux séries déjà connues avec des variantes de décor; ainsi à Nod, il semble que deux chapelles aient été ornées de cette façon, puisqu'il a été trouvé deux séries de rives avec des motifs différents. Le musée de Neuchâtel, en Suisse, conserve des fragments de corniche et de rives ornées de $\mathrm{S}$

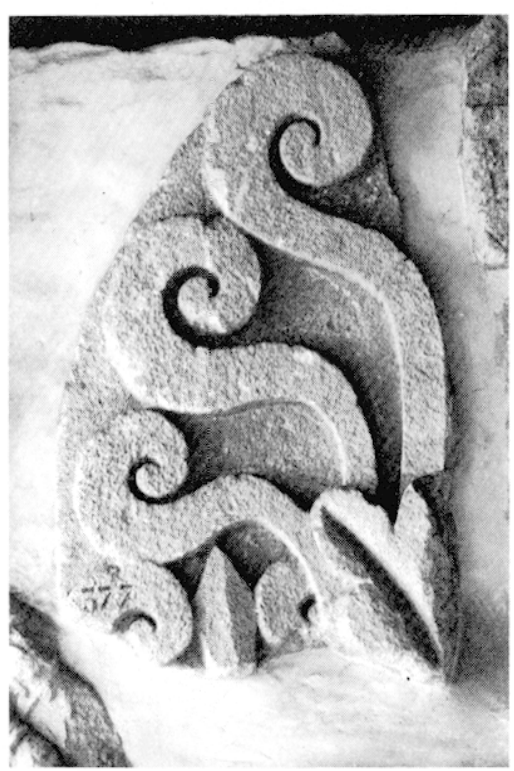

Fig. 27 - Langres, musée archéologique, acrotère incomplet surmontant l'amorce d'une rive ornée de $\mathrm{S}$. Dans son état actuel, ce bloc est haut de $91 \mathrm{~cm}$ et large de $58 \mathrm{~cm}$.

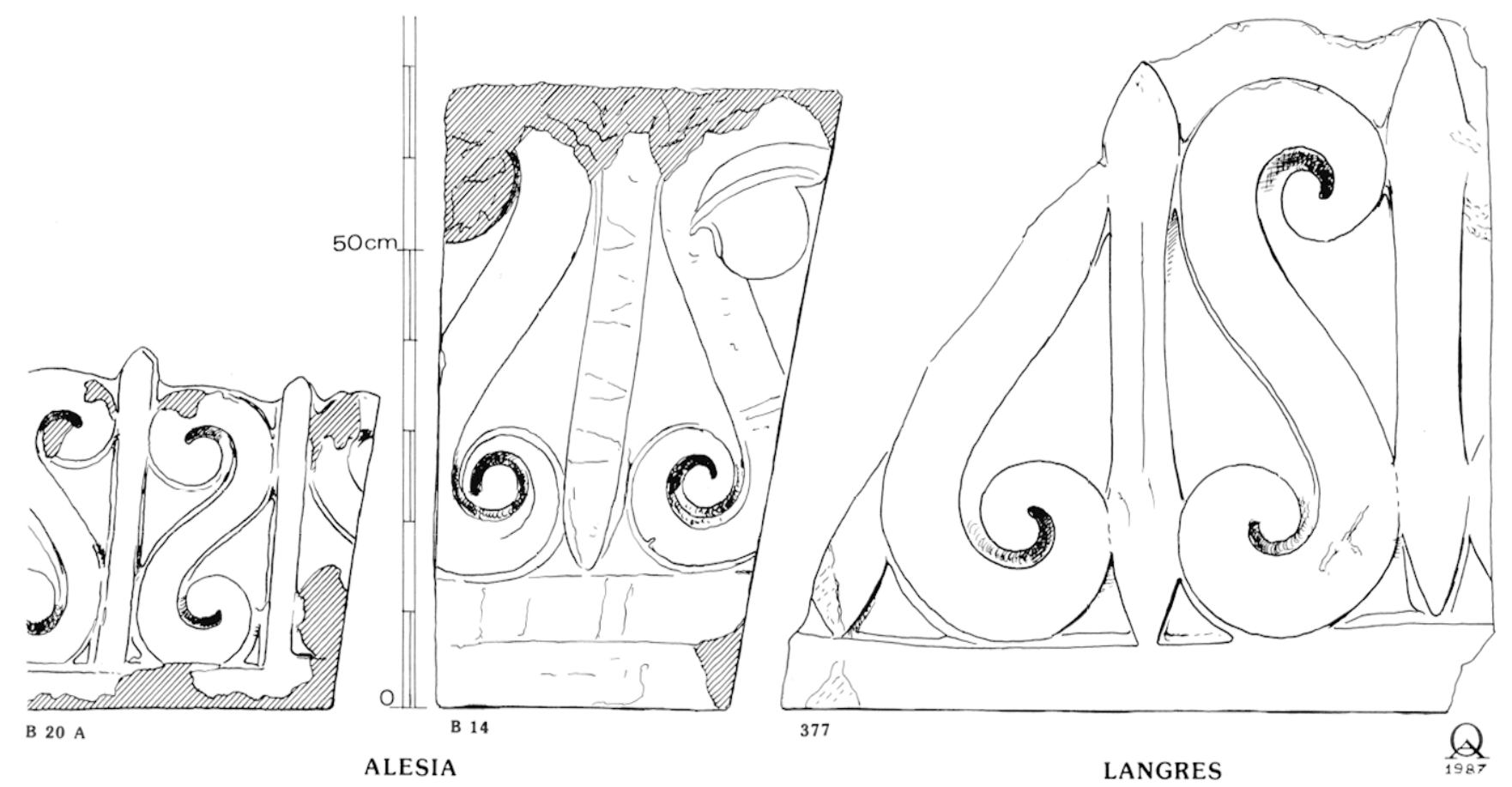

Fig. 28 - Présentation à la même échelle des rives de la chapelle de "la déesse aux amours" (B 20A), du temple d'Alésia (B 14) et de celle conservée au musée de Langres (377). Échelle $1: 10$. 


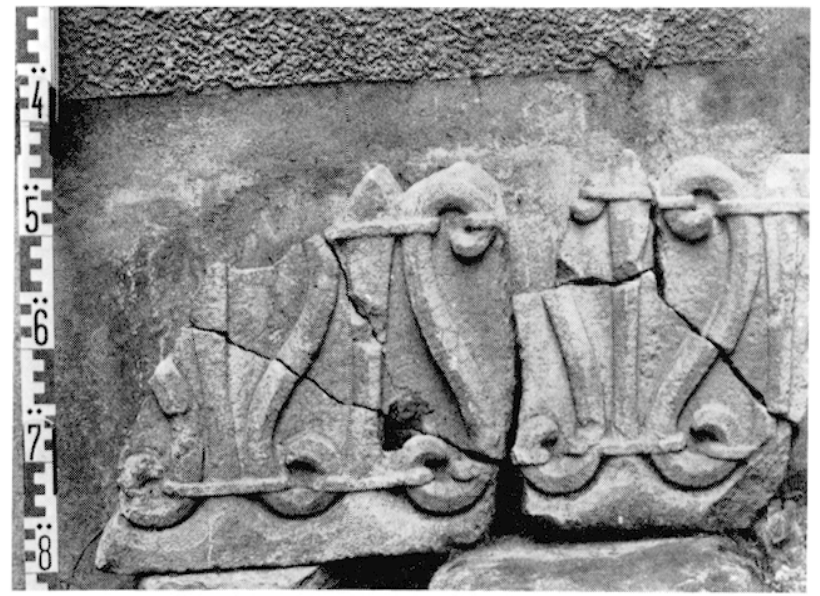

Fig. 29 - Langres, deux fragments de faittières, chacun formé de trois morceaux. Trouvaille fortuite.

agrémentées de hastes végétales, provenant du mausolée de Wavre, très proches de cette série ${ }^{47}$.

Ces décors de couronnement ont joui, semble-til, d'une certaine faveur et ont été reproduits sur des édifices de petites dimensions comme des stèles et même des édicules en terre cuite de l'Allier ${ }^{48}$.

\section{$\stackrel{* *}{* *}$}

Que conclure à la suite de cet inventaire des corniches d'Alésia?

En premier lieu, avec des réserves cependant, il a été possible de localiser ces corniches en les liant à plusieurs monuments d'Alésia : le théâtre, le monument à double colonnade, la chapelle de la «déesse aux amours", le temple, un bâtiment du sanctuaire de Moritasgus.

En ce qui concerne les éléments de datation, un début de réponse peut être apporté par l'analyse du

47 Ph. Brider, Le mausolée de Wavre, étude des fragments architecturaux du Musée archéologique de Neuchâtel, Jahrbuch der schweizerischen Gesellschaft für Ur-und Frühgeschichte, (annuaire de la socièté suisse de préhistoire et d'archéologie), 59, 1976, p. 193-201, pl. 29-34.

48 E. Rabeisen et $\mathrm{H}$. Vertrit, Les figurines galloromaines en terre cuite d'Alésia, Université de Bourgogne, Centre de Recherches sur les techniques gréco-romaines, Dijon, 1986, pl. 8-9; Autun Auguslodunum, capitale des Eduens, Musée Rolin, Autun, 1987, p. 278, $n^{\circ} 565$. Sur ces figurines, les $S$ droits et inversés ne sont pas toujours complets en hauteur : en effet quelquefois l'enroulement inférieur n'est pas représenté et le motif tend à ressembler à une suite de palmettes simplifiées. Le remontage du fronton d'Alésia a peut-être fourni l'explication de cette variante : la position reculée des rives par rapport au bord de la corniche fait que celle-ci tend à masquer le bas de celles-là pour un observateur qui se rapproche du monument; la fig. 17 en est l'illustration.

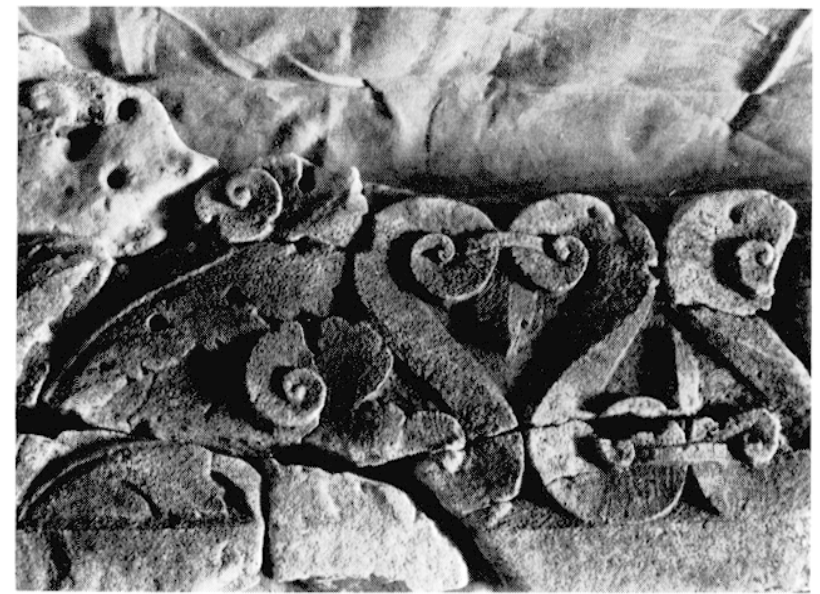

Fig. 30 - . Vod-sur-Seine, Côte-d'Or, rive ornée associèe à un acrotère d'angle à crosses végétales.

rapport $\mathrm{H} / \mathrm{L}, \mathrm{H}$ étant la hauteur et $\mathrm{L}$ la saillie prises toutes deux du bas du bloc au sommet du bandeau supérieur. Vitruve recommandait, au $\mathrm{I}^{\mathrm{er}} \mathrm{s}$. avant J.-C. de respecter pour les corniches ioniques le rapport $\mathrm{H} / \mathrm{L}=1$, c'est-à-dire de faire une saillie égale à la hauteur. Cette règle a-t-elle été respectée par ses successeurs dans les corniches modillonnaires régionales? A Alésia, seules deux corniches sont suffisamment complètes pour permettre le calcul exact de cette proportion : le rapport $\mathrm{H} / \mathrm{L}$ est égal à $1,04(22,5 / 21,5)$ pour le monument à double colonnade et de $0,95(31,5 / 33)$ à la chapelle de la "déesse aux amours". Il est possible, avec précaution, puisque les corniches sont en partie restituées, d'ajouter deux autres rapports : ceux des corniches de la plaine des Laumes, $1,02(28 / 27,5)$ et du théâtre, $0,98(32 / 32,5)$ (les deux autres corniches sont trop fragmentaires pour donner un résultat crédible). En classant ces rapports par ordre décroissant, 1,04, $1,02,0,98$ et 0,95 , ces corniches se situeraient dans l'ordre suivant : monument à double colonnade, plaine des Laumes, théâtre, chapelle. Cet ordre correspond bien à la chronologie relative de ces monuments entre eux telle qu'elle est envisageable dans l'état actuel de l'histoire du site. Ces chiffres montrent une évolution ver's une accentuation de la saillie par rapport à la hauteur, tout en restant proche du rapport d'équilibre $1 / 1$.

La prise en compte de ce rapport est plus concrète qu'elle ne peut paraitre $a$ priori : en effet, celui-ci correspond à l'épannelage final du bloc qui s'obtient à partir d'un gabarit : ce dernier décide de la saillie globale et de l'enveloppe de toutes les moulures.

Les éléments du décor sont si modestes, qu'ils n'apportent pratiquement pas d'éléments chronolo- 
giques ${ }^{49}$. Cependant les variations du motif du soffite peuvent être prises en considération : trois solutions se présentent : un soffite nu, un soffite à fleuron ne faisant pas saillie sur son cadre, un fleuron débordant. Dans la succession précédemment établie, une évolution apparaît du motif non saillant au motif débordant, ce qui correspond à une tendance constatée dans la grande architecture.

Un dernier élément est l'apparition du décor sur les métopes qui devrait être un indice chronologique, mais l'état actuel des publications ne permet pas de le situer exactement en Gaule.

A la suite de ces remarques, il semble possible d'isoler deux groupes : un au tournant de notre ère comprenant la corniche du monument à double colonnade avec ses modillons parallélépipédiques et celle de la plaine des Laumes, et un autre groupe à la fin du $I^{\text {er }}$ et du II" s. après $\boldsymbol{J}$.-C., sans pouvoir affiner la fourchette chronologique dans l'état actuel des recensements régionaux. Quoi qu'il en soit, l'étude des corniches est certainement fructueuse car ces éléments sont, de toute façon, porteurs d'enseignements sur la structure des parties hautes des monuments. En particulier, elle a permis ici de mettre en lumière, entre autre, un exemple d'agencement de couronnement qui n'appartient pas uniquement à des stèles ou des petits édifices, mais à de grands monuments. Cette constatation se trouve confirmée par un relief de Dieburg (RFA) qui représente en fond de décor un temple corinthien tétrastyle avec un fronton aux corniches modillonnaires couronné de rives ornées de $\mathrm{S}$ alternativement droits et inversés séparés par des hastes (fig. 31) ${ }^{50}$. Ce

49 Pierre Gros suggère cependant de rapprocher les rais de cocur alisiens des Scherenkymation (rais de cour "en ciseaux") qui, d'après l'étude récente de J. (iavz.spt, Zur Entwicklung lesbischer Kymationformen, Jahrbuch des deutschen archäologischen Institut, 98, 1983, p. 123 sq., ne pourraient pas descendre trop bas dans le $\mathrm{IJ}^{\mathrm{S}} \mathrm{s}$.

50) Dieburg, RFA, Kreis- und Stadtmuseum, n"Inv. 22052. La bibliographie concernant ce relief est donnée dans le catalogue Spätantile und frühes Christentum. Francfort, 1984. p. 540. Je remercie bien vivement $R$. Ilanoune de mavoir fait connaitre ce relief.

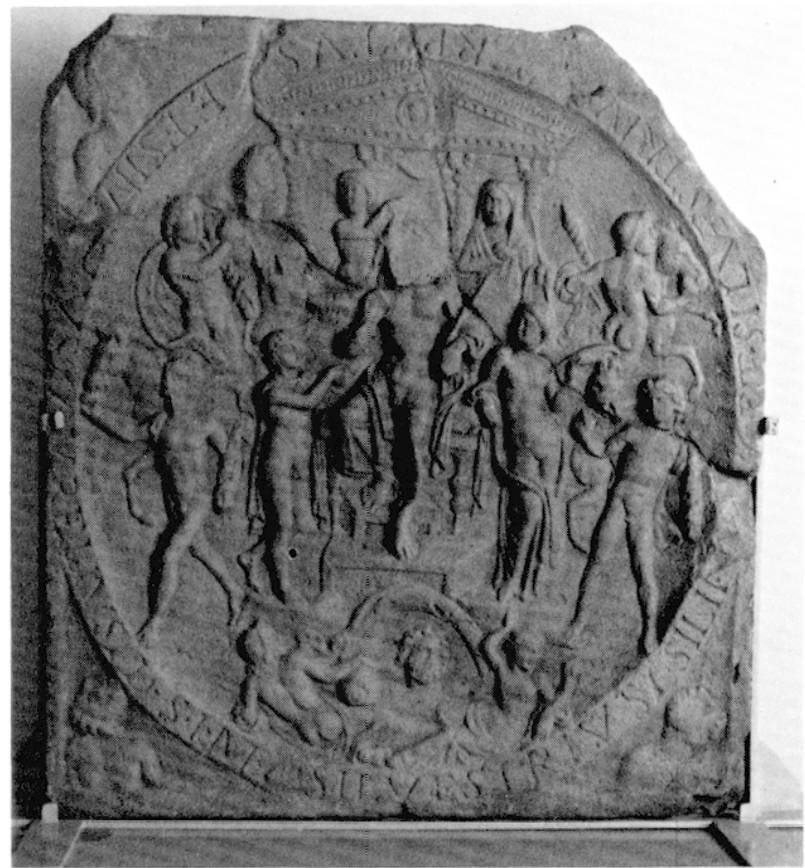

Fig. 31 - Dieburg, Kreis- und Stadtmuseum.

Revers d'un relief mythriaque. En haut, un temple tétrastyle avec un fronton surmonté de rives ornées de $\mathrm{S}$ alternativement droits et inversés.

relief incite à poser la question de la diffusion de cette forme architecturale : est-elle seulement régionale et liée aux couvertures de pierre ou d'ardoise?

\section{Albéric OlivieR*}

* Architecte au C.NRS, Bureau d'Architecture antique de Dijon.

N. B. - Toutes les figures sont de l'auteur, architecte au Bureau d'Architecture antique de Dijon, (relevés, dessins et photographies) à l'exception des relevés de J.-C. Barçon (C..RR, IDijon) : fig. 6,8 et 10 ; P. Varène (C.NRS, Aix-enProvence) : fig. 28, B 14.

Tous les blocs ont été relevés grandeur nature à la glace avec viseur orthogonal selon le procédé mis au point au BAAI), puis, réduits à la chambre claire. La documentation concernant ces figures est conservée au Bureau d'Architecture antique de IDijon, CNRS, L.P 5501. 36, rue Chabot-Charny. 